OECD Working Papers on Public Governance No. 35

\title{
Integrated Governance for Coherent Implementation of the SDGs in Egypt
}

Gamze Igrioglu,

Adam Ostry, Miriam Allam 


\section{Integrated Governance for Coherent Implementation of the SDGs in Egypt}




\section{OECD Working Papers on Public Governance}

OECD Working Papers should not be reported as representing the official views of the OECD or of its member countries. The opinions expressed and arguments employed are those of the author(s).

This document and any map included herein are without prejudice to the status of or sovereignty over any territory, to the delimitation of international frontiers and boundaries and to the name of any territory, city or area.

The statistical data for Israel are supplied by and under the responsibility of the relevant Israeli authorities. The use of such data by the OECD is without prejudice to the status of the Golan Heights, East Jerusalem and Israeli settlements in the West Bank under the terms of international law.

(C) OECD 2020

You can copy, download or print OECD content for your own use, and you can include excerpts from OECD publications, databases and multimedia products in your own documents, presentations, blogs, websites and teaching materials, provided that suitable acknowledgment of OECD as source and copyright owner is given. All requests for commercial use and translation rights should be submitted to rights@oecd.org. 


\section{Foreword}

The Sustainable Development Goals (SDGs) set a roadmap for achieving a better and more sustainable future for all. The crosscutting nature of the SDGs requires governments to work across policy areas and presents a multidimensional governance challenge. The capacity of governments to plan, co-ordinate, steer, monitor and evaluate the implementation of the SDGs is critical for achieving progress and delivering on Agenda 2030.

The Government of Egypt has embarked on an ambitious reform agenda to achieve the SDGs and has focussed on strengthening the governance of SDGs. Within the framework of the joint UN-OECD MAPS (Mainstreaming, Acceleration and Policy Support) Engagement on SDG Implementation, the OECD, in collaboration with the UNDP, UNFPA and UNICEF, has undertaken an assessment of Egypt's institutional and decision-making framework governing the implementation of the SDGs. The assessment highlights that a number of governance practices and tools could support Egypt's ongoing efforts towards SDG implementation, including strengthened leadership capacities and skills, which are needed to navigate the complexities of SDG implementation, as also highlighted in the 2019 OECD Recommendation on Policy Coherence for Sustainable Development. The assessment is also a pilot for a joint OECD-UNDP project to support countries in their SDG implementation.

This paper presents the findings of the OECD's assessment, suggests good practices and makes specific policy recommendations for effectively implementing the SDGs. In particular, it identifies Egypt's key strengths and challenges under three governance themes: institutional and decision-making arrangements; governance tools; and monitoring, evaluation and feedback loops. The paper then concludes with a set of tailored policy recommendations based on OECD country practices. This paper also seeks to benchmark Egypt's arrangements using the OECD instruments that codify good practices and standards in public governance, in particular the OECD Recommendations of the Council on Policy Coherence for Sustainable Development; Open Government; Regulatory Policy and Governance; Gender Equality in Public Life; Budgetary Governance; and Public Service Leadership and Capability.

This paper draws on the OECD's expertise and policy knowledge acquired through dialogue among peercountries in its public governance committees, its networks in the MENA-OECD Governance Programme, as well as through extensive evidence drawn from its assessment work in crosscutting and thematic public governance reviews. It also supports knowledge gathering and peer learning initiatives in support of SDG implementation. Finally, by presenting the results from the joint OECD-UNDP assessment and key recommendations, the paper intends to benefit the proposed Hub on the Governance for the SDGs, which would aim to help countries build governance capabilities and leadership in support of the SDGs. 


\section{Acknowledgements}

This working paper was prepared by the OECD Public Governance Directorate under the leadership of Marcos Bonturi, Director and of Martin Forst, Head of its Governance Reviews and Partnerships Division.

The working paper was written by Gamze Igrioglu, Policy Analyst, under the guidance of Adam Ostry, Head of Unit, Public Governance Reviews, and Miriam Allam, Head of the MENA-OECD Governance Programme. The authors thank OECD colleagues Tatyana Teplova, Sara Fyson, Eva Beuselinck, Hendrik Bosshammer, Brian Finn, Peter Vagi, Pinar Guven, Amira Tlili, Charlotte Denise-Adam, Manon Epherre Iriart, Guillaume Biganzoli and Mohamed Refai from the Public Governance Directorate for their contributions. The suggestions and comments provided by the Development Co-operation Directorate during the internal peer-review process are gratefully acknowledged. Particular thanks are expressed to Eric Bensel and Rachel Scott from this Directorate.

The OECD would like to thank the Government of the Arab Republic of Egypt, especially the Ministry of Planning and Economic Development (formerly called as the Ministry of Planning, Monitoring and Administrative Reform) ${ }^{1}$, for its active engagement, co-ordination and assistance in completing this working paper. In particular, the OECD thanks H.E. Dr. Hala El Said, Minister of Planning and Economic Development, Deputy Minister Ahmed Kamaly, Ambassador Khaled Shamaa, Haytham Diab, Ramy Taha and Aya Nawwar for their commitment to the partnership.

The OECD wishes to acknowledge the co-operation of public officials from the Ministry of International Cooperation; the Ministry of Foreign Affairs; the Ministry of Finance; the Ministry of Local Development; the Ministry of Higher Education and Scientific Research; the National Council for Women; the Cabinet Information and Decision Support Centre (IDSC) and the Central Agency for Public Mobilisation and Statistics, who participated in meetings and a high-level roundtable organised by the OECD in September 2018 in Cairo. The OECD thanks H.E. Yasmine Foaud, Minister of Environment; H.E. Ghada Wali, Minister of Social Solidarity; H.E. Ezz el-Din Abu-Steit, Minister of Agriculture and Land Reclamation; H.E. Amr Adl Bayoumi, Minister of Supply and Internal Trade; H.E. Maya Morsi, President of the National Council for Women and high-level representatives for participating in the high-level debrief of the MAPS Engagement in Egypt in October 2019.

The OECD also wishes to thank the UN agencies (UNRC, UNDP, UNFPA and UNICEF) and the World Bank for their cooperation. In particular, the OECD thanks Richard Dictus, UN Resident Coordinator; Randa Aboul-Hosn, UNDP Resident Representative; Roqaya Dhaif and Michael Schaadt for coordinating the MAPS Engagement in Egypt.

Daisy Knox-Murphy and Robin Houng Lee provided logistical support for the preparation of this working paper; Andrea Uhrhammer, Roxana Glavanov and Lukasz Lech provided editing and publishing support.

\footnotetext{
1 The Ministry of Planning and Economic Development was called as the Ministry of Planning, Monitoring and Administrative Reform, while the UN MAPS Engagement was conducted from September 2018 to October 2019.
} 


\section{Table of contents}

OECD Working Papers on Public Governance 2

Foreword 3

Acknowledgements 4

$\begin{array}{ll}\text { Executive Summary } & 7\end{array}$

Introduction 12

$\begin{array}{ll}\text { References } & 17\end{array}$

1 Institutional and Decision-Making Arrangements for SDG Implementation in Egypt 18

$\begin{array}{lr}\text { Significance of institutional and decision-making arrangements } & 18\end{array}$

Key strengths $\quad 18$

Key challenges $\quad 20$

References $\quad 22$

2 Governance Tools for SDG Implementation in Egypt 23

Significance of governance tools 23

Key strengths $\quad 25$

Key challenges $\quad 26$

References $\quad 28$

3 Monitoring, Evaluation and Feedback Loops for SDG Implementation in Egypt $\quad 29$

Significance of monitoring, evaluation and feedback loops 29

$\begin{array}{ll}\text { Key strengths } & 31\end{array}$

Key challenges $\quad 32$

References 33

4 The Way Forward $\quad 34$

Specific Recommendations $\quad 34$

References $\quad 45$ 
Figures

Figure 1.1. Institutional mechanisms in place to implement the SDGs vary across countries

\section{Boxes}

Box 1.1. Rationale for the CoG leading the SDGs

Box 1.2. The proposed Hub on the Governance for the SDGs

Box 2.1. Aligning the national budget with the SDGs 24

Box 3.1. Monitoring and Evaluation of the SDGs 30

Box 4.1. The centre-of-government coordination of the SDGs $\quad 36$

Box 4.2. Strengthening vertical coordination $\quad 38$

Box 4.3. Assessing performance for impact $\quad 39$

Box 4.4. Institutionalising stakeholder consultation $\quad 40$

Box 4.5. Strengthening evidence-based policymaking 42

Box 4.6. Strategic use of performance indicators 42

Box 4.7. Sound monitoring and evaluation systems 43

Box 4.8. Integrating national gender equality strategies into SDG agendas $\quad 44$ 


\section{Executive Summary}

This working paper is prepared as part of United Nations' MAPS (Mainstreaming, Acceleration and Policy Support) Engagement with the Government of Egypt on SDG Implementation. Within this framework, the OECD, in collaboration with UNDP, UNFPA and UNICEF, has conducted an analytical assessment on Egypt's institutional framework governing the implementation of the SDGs. The paper draws on the findings of a series of face-to-face meetings conducted with the public officials from nine ministries and government bodies, which were discussed and validated during a high-level round-table organised by the OECD in September 2018 and ministerial debrief in October 2019. This paper refers to these Ministries, which participated in the MAPS Engagement during this period (and uses the Ministry nomenclature in force at the time).

The Government of Egypt has embarked on an ambitious reform agenda to achieve key strategic objectives for the country's growth and development by 2030. The Government has also demonstrated a strong commitment at the highest political level to achieving the Sustainable Development Goals (SDGs). This commitment has been translated into a strategic framework through the national "Sustainable Development Strategy: Egypt Vision 2030" (SDS), which is Egypt's first such strategy and which guides ongoing reform efforts.

Despite significant progress, evidence from across the OECD suggests that a number of governance practices and tools would boost Egypt's efforts in pursuing the SDGs and could help Egypt unlock its untapped potential to improve inclusive and sustainable growth outcomes over time.

This OECD paper assesses Egypt's governance framework for implementing the SDGs across three building blocks of integrated public governance, each discussed in a separate chapter:

1. Institutional and decision-making arrangements;

2. Governance tools; and

3. Monitoring, evaluation and feedback loops.

It identifies Egypt's key strengths and challenges in each of these areas and assesses them vis-à-vis good practices in OECD countries. The paper then concludes with a set of specific policy recommendations tailor-made for the case of Egypt, based on OECD country practice.

In particular, the OECD assessment highlights the advances Egypt has made in implementing the SDGs in recent years. These include strong commitment and ownership at the highest political level, the preparation of the first sustainable development strategy of Egypt and the launch of institutional coordination mechanisms, monitoring and evaluation systems, data-generation, performance and programme-based budgeting, and stakeholder consultations.

Despite progress, there is room to improve Egypt's institutional framework governing the implementation of the SDGs. In particular, vertical and horizontal cross-government co-ordination led by the centre of government could be strengthened, in part by institutionalising these co-ordination mechanisms. Other areas for improvement include enhancing capacity and skills in line ministries and subnational authorities; increasing the availability of, and accessibility to, quality and disaggregated data and performance 
indicators aligned to the SDGs; and optimising the use of key governance instruments and tools (i.e. results-based budgeting, stakeholder consultations and impact assessments).

A strong institutional framework is also essential for promoting gender equality, one of the 17 Sustainable Development Goals (SDG 5) and integral to all dimensions of inclusive and sustainable development. In conducting this assessment, the OECD was asked to pay attention to the implementation of SDG $5 .{ }^{2}$ While it is beyond the scope of this paper to provide a comprehensive overview of the institutional arrangements governing gender equality efforts in Egypt, the paper makes special references to this issue where possible, and presents, in the concluding chapter, a set of policy messages on building gender equality building based on what works in OECD countries.

In light of the OECD's assessment, this paper highlights the following areas where further efforts could help achieve the SDGs. By nature, the sequencing and implementation of the recommendations require political commitment, as set out below, as well as available capacities and resources:

- Sustain high-level political commitment and support for the effective implementation of the SDGs. This could also help reinforce the commitment and ownership of all parties engaged in the SDGs. In doing so, the Government may wish to consider making a formal announcement on the level of priority it assigns to the effective implementation of the SDGs. It could also consider aligning this commitment across the government through mandate letters to Ministers and senior civil servants; and to integrating work on the SDGs into the annual performance evaluation of senior public officials, as a measurement of how they are contributing, from both a strategic and an operational perspective, to advancing the Government's SDG agenda. Furthermore, information related to the implementation of the SDGs and SDS, including decisions taken at the National Committee as well as performance evaluations, could be made public in order to generate buy-in, sustain support, commitment and ownership across society, and generate public trust in the ongoing reform agenda. The UN Voluntary National Reviews on the SDGs could be leveraged to demonstrate and sustain high-level political commitment for effective implementation of the SDGs.

- Optimise the use of centre-of-government institutions (CoG) in enabling a whole-of-government approach to SDG implementation; reinforce the role of the CoG through the involvement of Prime Minister's and Presidential offices in leading the pursuit of the SDGs. Currently, the main CoG institutions leading SDG implementation are the Ministry of Planning, Monitoring and Administrative Reform ${ }^{3}$ and the Ministry of Finance. The efforts underway to establish a "High Council for Planning and Sustainable Development" under the leadership of the President and including the Prime Minister demonstrate the necessity to involve the Prime Minister's and President's offices in leading SDG implementation. It should be noted that in two-thirds of the OECD countries, these offices lead the SDG implementation efforts, since they have expertise in working on crosscutting policy areas and possess the convening power to mobilise all government bodies across all levels of the administration.

- Ensure that the sustainable development strategy (SDS) is part of a broader "whole-of-government" approach for SDG governance and supported by policy tools such as impact assessments and results-based budgeting. This would also include an effective and systematic application of regulatory impact assessments (RIA), sustainable impact assessments (SIA), and environmental impact assessments (EIA) across policy areas. The use of these tools needs to be

\footnotetext{
2 SDG 5: Achieve gender equality and empower all women and girls.

3 The Ministry of Planning, Monitoring and Administrative Reform is officially named as the Ministry of Planning and Economic Development as of December 2019.
} 
embedded in a broader results-based management approach respecting all dimensions of management and decision-making to achieve the SDGs.

- Institutionalise the application of public consultation mechanisms in the formulation, implementation and monitoring of SDG plans across levels of government. Further efforts should focus on establishing a uniform framework clearly outlining how diverse stakeholders from the public, civil, academic and private sectors can be involved in all phases of the policy cycle and in service design and delivery. This could also help foster transparency, ownership and commitment across society by enabling a citizen-centred and participatory approach to SDG implementation.

- Ensure multi-dimensionality in the design and implementation of the SDS while aligning all sector-based strategies with the SDS, national priorities and the SDGs themselves. For instance, establishing a formal framework of cooperation across government institutions for the development of sector-based strategies could optimise the alignment of all sector-based strategies with the SDS and SDGs. In addition, this could help all ministries work together, analyse the potential linkages in order to maximise multidimensionality within sector-based strategies as well as the coherence among them, and identify and manage tradeoffs and spill-overs successfully. The existing National Committee and the planned High Council could provide a platform for such collaboration and debate.

- As part of optimising the role of the CoG in whole-of-government strategysetting and steering, pursue the transition of the National Budget toward an integrated results-based budget, align the results-based budget areas with the sustainable development objectives for the country in the SDS, and ensure that these SDS objectives fully reflect the SDGs. This implies strengthening and sustaining institutional co-ordination between the Ministry of Planning, Monitoring and Administrative Reform and the Ministry of Finance (and the Presidency).

- Strengthen horizontal co-ordination by ensuring compliance with existing rules, formalise the co-ordination mechanisms in place and ensure their effective use. To be successful, the National Committee and the planned High Council should bring together all ministries and levels of government in pursuit of the SDGs. It is essential for Egypt to further institutionalise and formalise the structure of the National Committee and the planned High Council by further clarifying their competences, meeting frequency and working mechanisms. Furthermore, it is also critical to institutionalise SDG and equal opportunity units across all ministries with coherent, clear and effective mandates, structures and responsibilities.

- Strengthen vertical co-ordination by enhancing the administrative, policy and data-gathering capacity of the governorates, and ensure that regional and local priorities are reflected in the national strategy. In this regard, the ongoing efforts towards establishing a sub-committee at the governorate level would help enhance vertical co-ordination. Moreover, the participation of governorates in the National Committee and the planned High Council could help ensure that specific characteristics of different places in Egypt are reflected in the national strategy and action plans. A strong co-operation between the Ministry of Local Development and the Ministry of Planning Monitoring and Administrative Reform is also essential to steer the pursuit of the SDGs at the subnational level. Further attention could be paid to allocating clear responsibilities on the implementation of the SDGs within their mandates to enable joint efforts in this regard.

- Strengthen the collection, analysis, dissemination and use of quality data. Consideration could be given to ensuring an effective transition to results-based budgeting and linking the SDGs to programme areas in results-based budgeting; aligning KPIs; and making full use of the newly created electronic planning, 
monitoring, and evaluation system to align the budget allocations to the goals and key performance indicators of the SDS and SDGs. Egypt might further consider providing a clear mandate and adequate human and financial resources to the Central Audit Agency to conduct performance and value-for-money audits. Furthermore, there is scope for improving co-ordination across the centre of government institutions ( $\mathrm{CoG}$ ), data-collecting and producing bodies, line ministries and agencies as well as accountability and oversight bodies.

- Provide training and tools to strengthen the skills and capacities across the national government and across levels of governments to ensure the availability and accessibility of quality and disaggregated data as well as the analytical capacity to translate the data into policy-useful knowledge.

- Set measurable performance indicators aligned with the SDS and SDGs. Ensure the strategic use of performance indicators and data across the public sector to support the monitoring and evaluation of the impact of the sustainable development strategy and initiatives.

- Commit to reporting regularly on the implementation of the measures outlined in the sustainable development strategy. Regular monitoring and evaluation of implementation allows the government to measure the effectiveness of implementation and track progress over time. It also supports accountability, reveals potential bottlenecks and encourages the formulation of appropriate responses. Effective monitoring and evaluation could be ensured through formalising the strategic monitoring and evaluation systems and feedback loops; institutionalising and making full use of the National Committee and the planned High Council; and making the performance evaluation publicly available. It is also vital to strengthen accountability and oversight mechanisms for the effective implementation of SDGs and SDS. This implies providing the Central Audit Agency of Egypt with a clear mandate, capacity and resources to oversee and monitor the implementation of the SDGs on a regular basis.

- Pursue gender mainstreaming in the design, development, implementation and evaluation of all policy areas and budgets with a view to making progress in SDG 5, and support the implementation of SDS through a more gendersensitive lens. Consideration could also be given to institutionalising and formalising the co-ordination mechanisms between line ministries and the centre of government with the National Council for Women to pursue gender mainstreaming across all policy areas. Furthermore, Egypt might consider adopting gender impact assessment tools in support of evidence-based decision-making.

- Bolster the capacity and resources of the National Council for Women and of line ministries to develop, implement and monitor the National Strategy for the Empowerment of Egyptian Women 2030, and to enable a whole-ofgovernment approach across policy fields and SDGs. The OECD Recommendation on Gender Equality in Public Life (2015) stresses that gender equality institutions need to have sufficient capacity and resources to be able to coordinate a government-wide initiative and that placing these institutions at the highest level of government can provide them with visibility and authority.

- Strengthen accountability and oversight mechanisms for the effective implementation of the National Strategy for the Empowerment of Egyptian Women 2030 and gender mainstreaming. The 2015 OECD Recommendation underlines that independent institutions should have adequate mandates and capacity to monitor implementation of government-wide gender equality and mainstreaming policy. Further consideration could be given to mandating the Central Audit Agency of Egypt to provide oversight for implementing the National Strategy for the Empowerment of Egyptian Women 2030. 
- Adopt measures to achieve gender-balanced representation in parliaments, the judiciary and public administration and improve gender equality in public sector leadership. In the public sector, further consideration could be given to the use of proactive gender-sensitive and family-friendly people management policies such as work-life balance, flexible working hours, part-time work and maternity, paternal and parental leave arrangements. Furthermore, disclosure requirements, targets or quotas, open competition, clear recruitment standards and widely advertised vacancies could be used to promote equal access to opportunities in public sector leadership. As for the representation of women in the parliament, Egypt might consider reviewing the Law $46 / 2014^{4}$, which sets a minimum number of seats for women in the House of Representatives, with a view to increasing the number of women represented in the parliament. Consideration could be also given to introducing measures to ensure compliance with the law, such as through the rejection of non-compliant party lists by the electoral management body or financial penalties.

- Eliminate gender pay gaps in the public and private sectors as well as occupational segregation. Efforts could build on the labour law that guarantees equal pay for equal work through introducing systemic and regular pay assessments. In addressing this issue, consideration could be given to performing regular audits and establishing independent complaint and legal recourse mechanisms for non-compliance.

\footnotetext{
${ }^{4}$ The law sets a minimum number of seats for women in the House of Representatives. OECD (2018) Women's Political Participation in Egypt, http://www.oecd.org/mena/governance/womens-political-participation-in-egypt.pdf
} 


\section{Introduction}

In September 2015, 193 UN Member States adopted the 2030 Agenda for Sustainable Development, committing themselves to the 17 Sustainable Development Goals (SDGs). The 2030 Agenda represents a global commitment to "leaving no one behind" as well as a roadmap to balance economic growth, social development and environmental protection. The SDGs are a universal, collective responsibility; Agenda 2030 calls upon both advanced and emerging economics to take action. Driving the 2030 Agenda does not only aim to address the root causes of poverty, but also to contribute to inclusive economic growth and to enhance people's well-being in a sustainable manner.

The UN is currently leading a MAPS (Mainstreaming, Acceleration and Policy Support) Engagement with the Government of Egypt on SDG Implementation. Within this framework, the OECD, in collaboration with UNDP, UNFPA and UNICEF, has conducted an analytical assessment on Egypt's institutional framework governing the implementation of the SDGs on September 2018.

This paper builds on the OECD's expertise and extensive policy knowledge acquired through public governance committees, numerous public governance reviews as well as the OECD's principles and standards in the field such as gender equality, open government, budgeting and regulatory policy. In particular, the paper sheds light on the significance of integrated public governance in implementing the 2030 Agenda; assesses Egypt's governance framework; and provides good practices from the OECD and MENA countries as well as a set of tailor-made policy recommendations to enable integrated public governance in Egypt to deliver effectively on the SDGs.

Given the crosscutting nature of effective governance having an impact on all aspects related to the SDGs, the OECD's assessment aims to complement the work undertaken by UNDP, UNFPA and UNICEF in Egypt on SDG interlinkages and accelerators, SDG localisation and leaving no one behind. These efforts focus on providing analysis and policy recommendations while building on the most relevant OECD governance standards, good practices and tools whose implementation is also supported by the UN agencies' expertise and experience with local and regional-level implementation efforts as well as their ability to strengthen linkages with the broader UN system. These assessments also illustrate the importance of ensuring coherence and creating synergies across the activities conducted by different development partners. Therefore, the policy messages presented in this paper should be read in conjunction with the advice provided under other components of the MAPS Engagement ${ }^{5}$. More broadly, this paper's primary audience, beyond the Egyptian and UN stakeholders involved in this MAPS engagement, include decision makers, policy makers, public officials and the international community working on the 2030 Agenda for Sustainable Development.

The crosscutting nature of the SDGs ranging from climate action to reducing inequalities reveals a complex equation of complementarities and trade-offs across the whole spectrum of policy areas. This requires

\footnotetext{
${ }^{5}$ UNDP (2018), MAPS Engagement for Egypt 2018-2019, Mainstreaming Acceleration and Policy Support (MAPS) for SDGs, SDG interlinkages and potential accelerators, https://www.undp.org/content/dam/egypt/docs/Publications/Docs\%20SDGs/Policy\%20Note\%20SDGs\%20\%20MAPS\%20Engagement\%20for\%20Egypt\%202018-2019.pdf
} 
governments to align policies across silos and manage trade-offs coherently, notably by involving all parts of government as well as the private sector and civil society in strategic policy design, implementation and evaluation for results. Lack of institutional clarity, roles and responsibilities among governmental agencies as well as disjointed efforts undermine delivering on the SDGs in an effective manner. Hence, transforming our societies and delivering on the SDGs poses a multidimensional governance challenge.

According to the 65 Voluntary National Reviews (VNRs) presented by UN members to the UN High-level Political Forum (HLPF), coordinating across policy areas and enhancing policy coherence is identified as one of the most challenging aspects of pursuing the SDGs (OECD, 2018). This is also confirmed by the OECD's 2016 Survey on Planning and Co-ordinating the Implementation of the Sustainable Development Goals (SDGs) (OECD, 2016). The most prevalent challenges highlighted by the governments responding to the OECD survey include ensuring appropriate governance and coordination structures across ministries and levels of government; integrating the SDGs into the budget process; and building a large alliance with multiple stakeholders from the public, civil, academic and private sectors. It is worthwhile noting that many of the challenges in implementing and coordinating the SDGs are shared regardless of countries' income levels, a fact borne out through the survey results.

OECD experience demonstrates that pursuing integrated public governance is critical to overcome these challenges and to deliver effectively on the SDGs. In fact, one standout lesson from the Millennium Development Goals (MDGs) shows that it is essential for governments to work across policy areas by adopting an integrated approach to public governance, which overcomes policy and institutional silos and fosters institutional collaboration. ${ }^{6}$ This calls upon all governments to sustain robust institutional coordination frameworks as well as strengthen the quality of data systems and capacity for strategic, whole-of-government monitoring and evaluation.

In particular, adopting an integrated approach to public governance will enable countries to overcome the persistent governance challenges they face while implementing the SDGs through:

- enhancing whole-of-government co-ordination for more integrated policy-making that can better reflect the multidimensional nature of the SDGs;

- linking the results-based budgeting process with the national sustainable development policy agenda in a way that can reflect the SDGs, their national performance indicators, targets and result-areas;

- coherent, strategic approaches to sustainable development that reflect the strengths and assets of different regions and places in the country through better multi-level governance;

- more open, transparent, accountable and participatory governance to enable better engagement with citizens and stakeholders on the pursuit of the SDGs; and

- effective policy evaluation mechanisms demonstrating what works and what does not - to be able to alter course when results are sub-optimal.

Evidence across the OECD countries as well as the United Nations' Voluntary National Reviews (VNRs) demonstrate that the institutional arrangements that are being used to deliver on the SDGs vary across the countries (OECD, 2016). That said, a full third of the countries responding to the OECD survey reported that it is their centre-of-government institutions (CoG) (through the offices of Prime Ministers and Presidents) that lead the SDG implementation efforts (see Figure 1.1). Their experiences show that the SDG implementation coordinated by the CoG institutions has proven effective since these institutions have

\footnotetext{
${ }^{6}$ United Nations Development Group (2017), Guidelines to Support Country Reporting on the Sustainable Development Goals, http://sdgactioncampaign.org/wp-content/uploads/2017/04/guidelines-to-support-countryreporting-on-sdgs-1.pdf
} 
expertise in working on crosscutting policy areas and convening power to mobilise all government bodies across all levels (see Box 1.1).

The political mandate that comes from the Prime Minister's or President's offices also enables a policyneutral perspective to assess the potential trade-offs since they are not perceived as defending their own portfolio (OECD, 2017). Furthermore, in two-thirds of the OECD countries, the CoG institutions assume responsibility for leading the initiatives that support the implementation of the SDGs such as gender equality, poverty reduction, resource efficiency and climate action.

Based on these strengths, a few countries, such as Finland, that had previously mandated their Ministry of Foreign Affairs or Ministry of Environment to lead the SDG coordination had restructured the institutional set-up to ensure greater high-level political impetus by mandating the Government Office to lead the SDG coordination. $^{7}$

Figure 1.1. Institutional mechanisms in place to implement the SDGs vary across countries

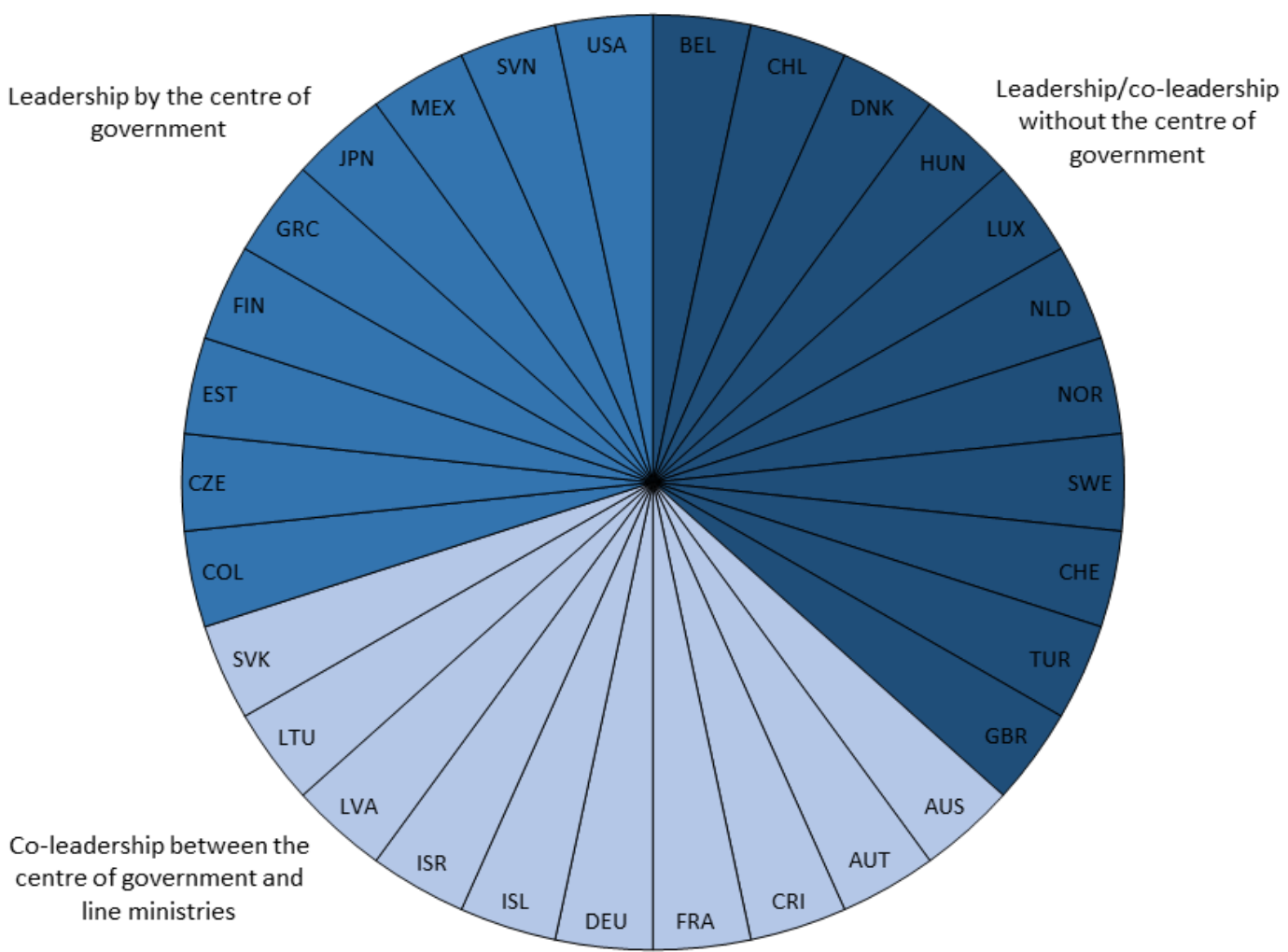

Source: OECD 2016 Survey on Planning and Co-ordinating the Implementation of the Sustainable Development Goals (SDGs) ${ }^{8}$

Another third of the respondents indicated that CoG institutions lead the SDG implementation jointly with other ministries. While, in the final third, the Prime Minister and Presidential offices are not involved in the SDG implementation at all. It is worthwhile to note that some of the responding countries also reported that they are still reflecting on how to best integrate the SDGs into their governance framework.

\footnotetext{
${ }^{7}$ National report on the implementation of the 2030 Agenda for Sustainable Development Finland, 2016

${ }^{8}$ On 25 May 2018, the OECD Council invited Colombia to become a Member. The date of membership will be the date of the deposit of Colombia's instrument of accession to the OECD Convention.
} 


\section{Box 1.1. Rationale for the CoG leading the SDGs}

- The CoG is technically policy neutral and therefore does not advocate for any onepolicy area. This is useful for an agenda as broad - and sometimes as politically sensitive - as the SDGs.

- Some SDGs may require trade-offs across sectors and policies need to be adjusted accordingly, which is a task the CoG is often best placed to support.

- The CoG has the convening power bestowed upon it by the head of government.

- The CoG has expertise in aligning policies and leading crosscutting initiatives. This is particularly useful given the breadth and scope of the SDGs, and the incentive for stakeholders to cherry-pick areas to implement that are the easiest and least costly to achieve.

- In the OECD survey, most Centres of Government (24 out of 32 responses) are currently leading initiatives that support the implementation of SDGs (e.g. gender equality, poverty reduction, resource efficiency, climate action and wellbeing).

- The CoG also has a role in localising the SDGs - and supporting vertical coordination - which is important as cities and local administrations will often have to take the initiatives to implement the SDGs.

Source: OECD 2016 Survey on Planning and Co-ordinating the Implementation of the Sustainable Development Goals (SDGs)

In the case of Egypt, as in many of the OECD countries, centre-of-government institutions (CoG) are best positioned and equipped to lead the SDG implementation efforts. The existing institutional framework governing the implementation of the SDGs underlines the importance for the Ministry of Planning, Monitoring and Administrative Reform and Ministry of Finance to steer the pursuit of the SDGs through enabling a whole-of-government approach. The ongoing efforts to establish "High Council for Planning and Sustainable Development" under the leadership of the President and with the membership of the Prime Minister demonstrate the necessity to involve the offices of Prime Minister and President among the CoG institutions leading the SDG implementation (see Chapter 1). This also implies the need to create strong cooperation between the Ministry of Planning Monitoring and Administrative Reform, Ministry of Finance and Prime Minister and Presidential offices on the pursuit of the SDGs. Therefore, it is crucial to ensure that institutional and decision-making arrangements governing the SDGs enable these institutions to work together collectively as the CoG institutions and to coordinate effectively across all line ministries and with the governorates.

OECD experience demonstrates that regardless of the approach taken to implement the SDGs, enabling integrated public governance is key to achieving the desired goals. Within the framework of integrated public governance, this paper assesses Egypt's governing framework on the SDGs, provides evidence and good practices from the OECD and MENA countries and outlines a roadmap for the way forward. In particular, the paper sheds light on the significant progress achieved by Egypt, identifies the potential bottlenecks and provides tailor-made policy recommendations in order to realise an integrated approach to the governance of the SDGs and to unlock Egypt's untapped potential.

The report underlines that it is essential for Egypt to build their ongoing reform efforts on a whole of a government approach supported by:

- institutionalised and effective ongoing vertical and horizontal coordination mechanisms across administrative silos within the national government, with the governorates and with municipal authorities; 
- the adoption and use of key governance instruments and tools (i.e. datageneration, especially performance data; results-based budgeting, stakeholder consultations and impact assessments) for more open, transparent, accountable and participatory governance to enable better engagement with citizens and stakeholders in the pursuit of the SDGs; and

- reporting regularly on the implementation of the measures outlined in the operational sustainable development strategy.

The effective application of these measures will be critical to complement the significant progress achieved with the preparation of the Sustainable Development Strategy: Egypt Vision 2030 and the ongoing efforts and initiatives led by the centre of the government (CoG).

For the purposes of this paper, Egypt's governing framework to implement the SDGs is assessed across three building blocks of integrated public governance, each outlined as separate chapters: institutional and decision-making arrangements; governance tools; and monitoring, evaluation and feedback loops. ${ }^{9}$ Each chapter provides country examples in boxes; these examples serve to illustrate good practices across the OECD and MENA countries, which could be useful for Egypt. In light of the analytical assessment of key strengths and challenges in each of these areas, the report concludes with a set of specific policy recommendations tailor-made for the case of Egypt, based on OECD country practice. Doing so, the paper also provides key insights for the proposed Hub on the Governance for the SDGs, which aims to help countries build governance capabilities and leadership in support of the SDGs (see Box 1.2).

\section{Box 1.2. The proposed Hub on the Governance for the SDGs}

Any government seeking to achieve the SDGs largely depends on the capacity and leadership skills needed to navigate the complexities of SDG implementation. In fact, institutions across different world regions face similar issues in fostering these governance capabilities. Leadership skills will also be essential for governments to effectively co-ordinate, consult and work across policy areas in new ways and develop integrated solutions, especially in the current COVID-19 crisis context which risks to slowing down or even reverse progress on a number of SDGs. Achieving the SDGs also requires multi-stakeholder efforts, leveraging science and technology.

The Hub on the Governance for the SDGs is proposed as a joint OECD-UNDP initiative to help countries build governance capabilities and leadership in support of the SDGs. The Hub would also help governments align the short-term responses to the consequences of the COVID-19 crisis with the achievement of long-term economic, social and environmental objectives for a sustainable recovery, in particular by assisting with integrated policy planning, whole-of-government mobilisation, strengthening stakeholder participation in the policy making cycle and enhancing monitoring and evaluation practices. The Hub would benefit from the OECD's analytical approaches and the UNDP's expertise in implementation support, facilitated by the UNDP's in-country presence around the globe. Building on the OECD Recommendation on Policy Coherence for Sustainable Development (PCSD), the Hub would focus on fostering leadership skills and policy coherence for sustainable development. The Hub would offer a global partnership where countries can collaborate on the governance challenges posed by the SDGs and seek targeted policy advice and implementation support that is tailored to their priorities and context.

The Hub is proposed to include an online knowledge platform to provide access to available knowledge on specific aspects of leadership and governance for the SDGs, including PCSD, and

\footnotetext{
9 The paper draws on the findings of a series of face-to-face meetings conducted with the public officials from nine ministries and government bodies, which were discussed and validated during a high-level round-table organised by the OECD in September 2018 as well as on data collected through a number of different channels including official documents, desk research and field data.
} 
make it more readily available, thereby facilitating the dissemination of evidence and learning worldwide. SDG leadership in action complementing the knowledge platform would be designed as country-specific activities to help build leadership, skills and institutional capacity for policy coherence for sustainable development and the broader implementation of the SDGs. This demand-driven support could include country-driven in-depth assessments identifying key leadership and governance challenges for SDG implementation. It would also support peer-to-peer exchanges to allow participating countries to benefit from existing networks, and support country twinning models. It could benefit from events, seminars, practical workshops and other implementation support aimed at participating countries so that they can discuss technical issues relating to strengthening the leadership and governance of SDG implementation. The collaboration with the UNDP would focus on providing support to developing countries to maximise the added value of both organisations. To that effect, technical support could be pursued using a proposed roster of experts.

\section{References}

OECD (2018), Policy Coherence for Sustainable Development 2018: Towards Sustainable and Resilient Societies, OECD Publishing, Paris. http://dx.doi.org/10.1787/9789264301061-en

OECD (2017), Getting Governments Organised to Deliver on the Sustainable Development Goals, https://www.oecd.org/gov/SDGs-Summary-Report-WEB.pdf

OECD (2016) Survey on Planning and Co-ordinating the Implementation of the Sustainable Development Goals (SDGs)

United Nations Development Group (2017), Guidelines to Support Country Reporting on the Sustainable Development Goals, http://sdgactioncampaign.org/wp-content/uploads/2017/04/guidelines-to-supportcountry-reporting-on-sdgs-1.pdf 


\section{Institutional and Decision-Making Arrangements for SDG Implementation in Egypt}

\section{Significance of institutional and decision-making arrangements}

From the public-governance perspective, lessons learned from implementing the Millennium Development Goals (MDGs) underscore the strategic importance of effective institutional and decision-making arrangements in delivering effectively on the SDGs. Institutional and decision-making arrangements lie beyond simple institutional roles and responsibilities. They encompass high-level political commitment and leadership, a whole-of-government, multi-dimensional sustainable development strategy that incorporates its economic, social and environmental dimensions into an integrated, coherent whole, as well as vertical and horizontal coordination mechanisms coupled with effective stakeholder-engagement capacity. In particular, experience of the OECD countries highlights the role of the centre-of-government institutions (through the offices of Prime Ministers and Presidents) in enabling a whole of a government approach to the implementation of the SDGs (see Introduction) (OECD, 2016a).

While there is no single framework for effective institutional and decision-making arrangements for sustainable development, a number of common good practices point to the need for governments to:

- identify current processes, institutions, actors, policies and mandates that affect implementation of the SDGs to build on strengths and address weaknesses; and

- tailor strategies, institutional mechanisms and coordination structures to optimise capacity to pursue the SDGs effectively.

This chapter assesses Egypt's current and planned institutional and decision-making arrangements governing the implementation of the SDGs by mapping out the current processes, institutions, actors, policies and mandates. In particular, institutional and decision-making arrangements in Egypt are analysed vis-à-vis political commitment and leadership, a whole of government strategy as well as vertical and horizontal coordination mechanisms in terms of key strengths and challenges to the implementation of the SDGs.

Chapter 4 outlines a set of key policy recommendations on how to strengthen these arrangements in light of international good practice in this area.

\section{Key strengths}

The Government of Egypt has embarked on an ambitious reform agenda to achieve key strategic objectives for the country's growth and development by 2030; and demonstrated a strong commitment to achieving the Sustainable Development Goals at the highest political level. This commitment has been 
translated into a strategic framework through the national strategy "Sustainable Development Strategy: Egypt Vision 2030" (SDS), which is the first sustainable development strategy of Egypt and guides ongoing reform efforts. The strategy adopted is aligned with the 17 SDGs, as well as the African Agenda 2063 (The Government of Egypt, 2016). In particular, it covers economic, social and environmental dimensions of SDGs and outlines strategic targets and sub-targets to achieve the goals; key performance indicators as well as expected challenges.

The strategy also strives to serve as a governing framework to ensure that all development programs and projects contribute to advancing SDGs. Within the framework of Egypt Vision 2030, a number of ministries and entities have developed their own sector-based strategies including the Ministry of Higher Education and Scientific Research, the Ministry of Trade and Industry, and the Ministry of Agriculture and Land Reclamation. Among them, the National Council for Women (NCW) has also launched a "National Strategy for Women's Empowerment 2030", which focuses on empowering women to accelerate the achievement of SDGs and demonstrates a good example of aligning sector-based strategies with the 2030 Agenda and SDGs.

In order to implement the SDS effectively, coordination mechanisms have been created to foster institutional collaboration and to mainstream SDGs successfully into national and subnational policies across sectors. Chief among them, the National Committee for Monitoring the Implementation of the Sustainable Development Goals has been established by prime-ministerial decree to act as an interinstitutional body responsible for monitoring the implementation of the SDGs. ${ }^{10}$ The composition of the National Committee has evolved since its creation in December 2015 to include stakeholders across different institutions. ${ }^{11}$ While the Committee was initially comprised of eight institutions based on the original decree, it is currently composed of representatives of seventeen ministries and state entities, ensuring a more inclusive approach. ${ }^{12}$ An ad-hoc technical sub-committee has been created to support the Committee. Although it was not established using formal legal or regulatory means, it is comprised of representatives of the Committee's members and is headed by the Ministry of Planning, Monitoring and Administrative Reform (in its capacity as the Committee's rapporteur). The Ministry of Planning, Monitoring and Administrative Reform (MoPMAR) reported that the sub-committee meets on a regular basis (usually once a month or when needed).

The draft law entitled "State Public Planning Law" proposes to establish a "High Council for Planning and Sustainable Development", under the leadership of the President of the Republic and with the membership of the Prime Minister and all relevant ministries in order to strengthen the coordination between different stakeholders, and monitoring and evaluation of the SDGs. The High Council for Planning and Sustainable Development is expected to replace the existing National Committee for Monitoring the Implementation of the Sustainable Development Goals once it enters into force. The draft law specifies that the Ministry of Planning, Monitoring and Administrative Reform will be presiding the technical secretariat of the High Council. The technical secretariat is to be established by a presidential decree and is to perform specific

\footnotetext{
10 The Government of Egypt, Prime Ministerial Decree, 3307 /2015

11 The Government of Egypt, Prime Ministerial Decree, 1410 /2017 and Amending Decree 1125 /2017

12 The Ministry of Social Solidarity, Ministry of Environment, Ministry of Investment and International Cooperation, Ministry of Local Development, Ministry of Education and Technical Education, Ministry of Higher Education and Scientific Research, Ministry of Planning, Monitoring and Administrative Reform, National Council for Women, National Council for Childhood and Motherhood, Ministry of Foreign Affairs, Ministry of Housing, Utilities and Urban Communities, Ministry of Health and Population, Ministry of Finance, Central Agency for Public Mobilization and Statistics, Accountability State Authority, National Council for Disability Affairs, and the Cabinet's Information and Decision Support Center.
} 
tasks including reporting to the High Council on the implementation of the development plans at the national and local levels. ${ }^{13}$

Sustainable development units and working groups have been established in different ministries to enhance inter-institutional coordination on the SDG implementation. These units are designed to act as focal points for raising awareness on SDGs, to ensure that sustainable development strategies within their own entities are aligned with the SDS and to facilitate the coordination and monitoring process, led by the Ministry of Planning, Monitoring and Administrative Reform (The Government of Egypt, 2018b). Additionally, Equal Opportunity Units have been established across different ministries in order to mainstream gender considerations and SDG 5 across all policy areas. ${ }^{14}$ In addition, the Central Agency for Public Mobilization and Statistics coordinates with various ministries including through the SDG Units to gather data related to SDG implementation and monitoring.

Regarding vertical coordination and coherence across government levels, while governorates are represented through Ministry of Local Development in the National Committee, there is a parliamentary proposal for the establishment of a subcommittee comprising the 27 governorates to monitor implementation of the SDGs. In line with the ongoing decentralisation efforts of Egypt, the Ministry of Planning, Monitoring and Administrative Reform is planning to undertake an assessment on localising the SDGs at the governorate level and to establish SDG units in each governorate. ${ }^{15}$

\section{Key challenges}

The current institutional setting, while illustrating key strengths and important potential in sustaining crosssilo coordination, poses several challenges to the effective delivery of SDGs in Egypt. Egypt could focus on addressing these challenges and strengthen the institutional and decision-making arrangements in order to reap fully the benefits of the ongoing efforts towards the SDGs.

\section{Strengthen policy coherence}

One of the key challenges derives from the difficulties in realising a whole-of government approach and ensuring policy coherence. In other words, challenges persist in integrating sector-based strategies and priorities of different institutions and stakeholders into a single multi-dimensional SDG strategy consisting of its macro (holistic view) and micro-level (sector-based) elements.

Interviews with key government stakeholders during the OECD's fact-finding mission ${ }^{16}$ highlighted that despite the multidimensionality of the Egypt Vision 2030 (SDS), sector-based strategies and plans tend to be developed within institutional silos, which undermines exploring SDG linkages across policy areas and capitalising on potential synergies. Although the Ministry of Planning, Monitoring and Administrative Reform has collaborated with certain line ministries while aligning their sector-based strategies to the SDGs, given that there is no formal framework requiring all ministries to work together and analyse the potential linkages, such cooperation remains at the discretion of the entities. The absence of specific

\footnotetext{
${ }^{13}$ The Government of Egypt (2018) Draft State Public Planning Law, https://goo.gl/K7pAvU

14 National Council for Women (2018) http://ncw.gov.eg/ar/\%D9\%88\%D8\%AD\%D8\%AF\%D8\%A7\%D8\%AA\%D8\%AA\%D9\%83\%D8\%A7\%D9\%81\%D8\%A4-\%D8\%A7\%D9\%84\%D9\%81\%D8\%B1\%D8\%B5/;

http://ncw.gov.eg/wp-content/uploads/2016/12/Equal Opportunities Unit Role in Ministries.pdf

${ }^{15}$ According to the official document provided by the Ministry of Planning, Monitoring and Administrative Reform on October 2018.

${ }^{16}$ Conducted over the week of 17 September 2018.
} 
regional SDG strategies that reflect the specifics of different places also poses challenges to the coherent implementation of the national strategy on SDGs at the regional level.

\section{Institutionalise the coordination mechanisms, including compliance}

The competences, working mechanisms and meeting frequency of the National Committee for Monitoring the Implementation of the Sustainable Development Goals are not specified by the establishing decrees. ${ }^{17}$ For instance, the responsibilities of the MoPMAR as the Rapporteur of the National Committee are not clearly expressed within the existing mandate of the Committee. Likewise, SDG units in line ministries appear to be ad hoc since only a couple of ministries currently have one. ${ }^{18}$ Equal Opportunity Units also seem to be established only in eight ministries, which may undermine consistent application of gender considerations across all policy areas. Additionally, Equal Opportunity Units are established by a ministerial decree of the relevant ministry, leaving the structure and responsibility of the unit at the discretion of the establishing entity and preventing a coherent approach (National Council for Women, 2018). Lack of institutionalisation of the coordination mechanisms restricts a unified approach to the communication and cooperation between government entities.

There is also room to improve vertical coordination through developing specific action plans and units on SDGs at the sub-national level, which are tailored to the needs and priorities of each governorate and, where feasible and appropriate, with municipal/local authorities. The localisation of the SDGs could take place through top-down and bottom-up processes: top-down leadership and steering, alongside bottom up action, engagement and ownership. The existing decoupling of national vision and strategies with the local actions and priorities limits successful implementation of the SDGs.

Furthermore, the SDGs tend not to appear explicitly in the mandates of existing institutions, which could limit institutional clarity, roles and responsibilities and contribute to an overlap or duplication in institutional mandates in this area. The OECD Recommendation on Policy Coherence for Sustainable Development (2019) underlines that integrating sustainable development goals into the mandate of existing institutions is essential to deliver effectively on the SDGs. Limited institutional clarity, roles and responsibilities among governmental stakeholders as well as mandate overlap/duplication can undermine the ongoing efforts to pursue the SDGs effectively. For instance, allocating clear responsibilities amongst the Ministry of Local Development, Ministry of Housing, and Ministry of Planning, Monitoring and Administrative Reform on the implementation of the SDGs into their mandates could enable a more coherent and unified approach to municipal/urban development initiatives that enables cities and towns to pursue SDGs more effectively. This would also help overcome the challenges stemming from limited institutional clarity.

\footnotetext{
17 The Government of Egypt, Prime Ministerial Decrees 3307 /2015 and 1410/2017

${ }^{18}$ According to the official document provided by the Ministry of Planning, Monitoring and Administrative Reform.
} 


\section{References}

OECD (2019) OECD, Recommendation of the Council on Policy Coherence for Sustainable Development, https://www.oecd.org/gov/pcsd/recommendation-on-policy-coherence-for-sustainabledevelopment-eng.pdf

OECD (2018), Policy Coherence for Sustainable Development 2018: Towards Sustainable and Resilient Societies, OECD Publishing, Paris. http://dx.doi.org/10.1787/9789264301061-en

OECD (2016) Survey on Planning and Co-ordinating the Implementation of the Sustainable Development Goals (SDGs)

The Government of Egypt (2018a) Draft State Public Planning Law, https://goo.gl/K7pAvU

The Government of Egypt (2018b) Egypt's Voluntary National Review

https://sustainabledevelopment.un.org/content/documents/20269EGY VNR 2018 final with Hyperlink 9720185b45d.pdf

The Government of Egypt (2016) Sustainable Development Strategy: Egypt Vision 2030 http://sdsegypt2030.com/wp-content/uploads/2016/10/1.-Introduction.pdf

National Council for Women (2018)

http://ncw.gov.eg/wpcontent/uploads/2016/12/Equal Opportunities Unit Role in Ministries.pdf 


\section{Governance Tools for SDG Implementation in Egypt}

\section{Significance of governance tools}

Integrated public governance entails the presence and systemic application of a set of governance tools, which can support governments in their efforts to successfully implement the SDGs. Having quality data and evidence, skills and resources in the government's workforce as well as strategic performance, monitoring and evaluation tools such as performance-based budgeting, impact assessments and stakeholder engagement in place are essential to deliver effectively on the SDGs.

Informed decision-making and evidence-based policymaking is critical for the effective implementation of the SDGs. In particular, setting the right quantitative outcome-based performance targets allows governments to establish an accurate picture of reality. It grounds SDGs in national and local realities by reflecting the specifics of countries and differences across regions. Indicators and targets on the SDGs builds an evidence base for revealing gaps, designing policy interventions and evaluating their impacts. This also allows results to be tracked vis-à-vis national and international SDG targets and benchmarks; and enables both sound evidence-based policy making; as well as monitoring and evaluation. It is also vital to ensure that national data collection efforts are aligned with national goals for sustainable development to reveal and address the existing challenges.

Likewise, having adequate capacity, skills and resources is equally important to be able to advance Agenda 2030 and the SDGs. It is crucial that public officials across the levels of government are adequately equipped with strategic planning, coordination, policy analysis, data gathering and processing skills. This necessitates providing line ministries, government agencies and governorates with sufficient capacities (e.g. training and knowledge) and resources (e.g. budget and staff) to implement sustainable development strategies and policies, and to assess the impacts of their work.

Planning tools and requirements are also crucial to implement the SDGs. Among them, budgeting is one of the significant instruments of government policy and planning, as the budget reflects a government's spending priorities. The OECD Policy Recommendation of the Council on Budgetary Governance underlines the significance of aligning budgets with the medium-term strategic priorities of government and structuring the budget allocations in a way that corresponds with national objectives (OECD, 2015). It also calls upon governments to ensure that performance, evaluation and value for money are integral to the budget process. No development plan can be successful without securing adequate resources. Integrating the SDGs into the budget process helps ensure that the collection and allocation of public resources is carried out in ways that contribute to both the SDGs and to national development goals (OECD, 2017).

In addition, as more and more countries move from line item to performance-based budgeting, the result areas in performance budgets need to mirror the sustainable development objectives of the country as well as the SDGs. Indeed, countries that do not adopt a results-based fiscal framework may face challenges to measure the impact of spending on the pursuit of the SDGs, because line item budgeting does not allow them to measure fiscal performance as a function of the pursuit of strategic goals and 
outcomes. Being able to measure whether public funds earmarked for the construction of a school actually led to the building of the school does not enable a government to measure whether that school has led to better educational outcomes, better jobs and less poverty.

Several OECD countries including Mexico and Norway have been using performance-based budgeting to align all their projects and programmes with the SDGs (see Box 2.1) (OECD, 2018). Hence, it is critical to ensure that performance, evaluation and value for money are integral to the budget process and are clearly linked with the SDGs.

\section{Box 2.1. Aligning the national budget with the SDGs}

\section{Norway}

Following the adoption of the 2030 Agenda, the Government of Norway has incorporated the national reporting mechanisms on the SDGs into the budget process. The Ministry of Finance is responsible for ensuring a co-ordinated budget to foster SDG implementation and allocates each of the 17 SDGs to a specific co-ordinating ministry. These ministries collaborate with other ministries involved in following up the relevant targets. Ministries prepare annual progress reports, which are submitted to the Ministry of Finance.

The Ministry of Finance incorporates the progress report on the implementation of the SDGs as a White Paper in the national budget, which is presented annually to the Norwegian Parliament along with the state budget. This engages the parliament in a constructive dialogue on the 2030 Agenda and ensures annual reporting on the follow-up of the SDGs to the Parliament through a formalised process.

At the sub-national level, the government uses existing mechanisms for co-operation with local and regional authorities, such as regular consultations between the central government and local authorities. Consultative meetings take place as plenary and bilateral meetings between the Norwegian Association of Local and Regional Authorities and the ministries. These meetings serve as a platform for dialogue in discussing the distribution of revenues in relation to the tasks carried out by the local authorities, the financial situation of the local authorities, and efficiency measures. The consultations also include arrangements for involving the Norwegian Association of Local and Regional Authorities in the ministries' studies on the cost of reforms, and impact assessments on how legislative proposals affect the municipalities.

\section{Mexico}

The experience of Mexico highlights that national planning and budgetary processes provide vital tools to advance the SDGs. In Mexico, the National Planning Law was updated in 2017 to give mandates to all federal administrations on the implementation of the 2030 Agenda. A Specialised Technical Committee on the SDGs (CTEODS) was formed with the leadership of the Office of the President and the Institute of Statistics and Geography. The technical committee developed a framework with the Ministry of Finance to integrate planning, public finance management, policy making and oversight to support the achievement of the SDGs.

Within this framework, the Ministry of Finance has identified mechanisms to link budget allocations with the SDGs with a view to strengthening strategic planning, monitoring and evaluation. In particular, The Ministry of Finance identified specific budget items and estimated the allocation sufficient to contribute to progress on the SDGs through using a results-based management perspective.

The application of results-based budgeting framework has enabled Mexico to acquire necessary information to:

- identify the link between the current national planning and SDGs;

- assess the percentage of SDGs linked to government programmes and, conversely, the number of programmes linked to each SDG; 
- communicate the country's starting point and what has been achieved;

- make public policy decisions and budget allocations based on an initial analysis of how much is currently invested in each SDG.

Source: Norway's follow-up of Agenda 2030 and the Sustainable Development Goals - Ministry of Foreign Affairs (2016)

https://www.regjeringen.no/globalassets/departementene/ud/vedlegg/utvikling/sdg_rapport_full_en.pdf

OECD (2018), Policy Coherence for Sustainable Development 2018: Towards Sustainable and Resilient

Societies, OECD Publishing, Paris.http://dx.doi.org/10.1787/9789264301061-en

Thus, this chapter assesses the effectiveness of governance tools on driving the implementation of the SDGs in Egypt in relation to quality data and evidence, capacity, skills and resources as well as planning tools and requirements in terms of key strengths and challenges.

\section{Key strengths}

The Central Agency for Public Mobilization and Statistics (CAPMAS) is the official statistical agency of Egypt; it collects, processes, analyses, and disseminates statistical data and conducts the census including on the SDGs. ${ }^{19}$ There is a specialised unit for SDGs in CAPMAS, which focuses on the development of indicators related to the SDGs. The SDG unit is responsible for the classification, identification and measurement of indicators used in both the SDGs and the SDS (The Government of Egypt, 2018a). Another important responsibility of CAPMAS relates to the preparation of the periodical national statistics report on the SDGs. The first national statistical report of Egypt on the SDG indicators was launched in May 2018 (CAPMAS, 2018). Building on the global framework on tier classifications for the SDGs, this report demonstrates the availability of data in Egypt vis-à-vis the specific indicators set globally on each SDG target. Based on the level of methodological development and the availability of data, $43 \%{ }^{20}$ of the SDG indicators in Egypt are currently classified under Tier 1, indicating standards are clear and available, and data is regularly produced. ${ }^{21}$

Additionally, CAPMAS issues a bi-annual report formulated as a research study of population in Egypt. The report provides statistics on education status, literacy and school dropout rates, marriage and divorce patterns and health disaggregated by age, sex, educational background and disability in a comparative manner from 2006 to 2017. The report also lays out an overview of key statistics on women's status in education and employment from 2005 until 2017 to track the progress towards achieving the SDGs (CAPMAS, 2018).

In order to strengthen capacities and skills across the government to implement the SDGs, the Ministry of Planning, Monitoring and Administrative Reform has organised a number of capacity building activities including training on awareness raising, monitoring and evaluation as well as training of trainers. ${ }^{22}$ Several capacity-building activities have also been conducted by some of the line ministries including the Ministry of Finance and Ministry of Local Development. For instance, the Ministry of Finance in collaboration with the Ministry of Planning, Monitoring and Administrative Reform organised a series of technical training activities and workshops with the ministries piloting programme and performance-based budgeting in order to discuss how to apply programme and performance-based budgeting in Egypt's state budget (The

\footnotetext{
19 The Government of Egypt, Presidential Decree 2915/1964

20 Document provided by CAPMAS (2018)

21 Tier 1 indicators are conceptually clear, has an internationally established methodology and standards are available, and data is regularly produced by countries and in every region where the indicator is relevant.
}

22 Document provided by the Ministry of Planning, Monitoring and Administrative Reform, Sustainable Development Unit (2018). 
Government of Egypt, 2018a). The Ministry of Local Development has established a local development centre in Sakkara to train the local administration units (The Ministry of Local Development, Egypt, 2017). The ongoing capacity building efforts has helped raise awareness across the government on the SDG and SDS priorities and created committed change-agents across the public administration willing to drive the SDG and Egypt Vision 2030 agenda.

Regarding the planning tools and requirements, Egypt is gradually undertaking a process of managing the transformation from line-item budgeting to programme and performance-based budgeting. The transition to programme and performance-based budgeting (which has been piloted in 16 ministries and is planned to be piloted in 6 more ministries) ${ }^{23}$ aims to overcome the existing challenges in linking the national budget to the SDGs. In order to facilitate the implementation of programme and performance-based budgeting, the Ministry of Finance has developed a unified template, which is to be accompanied with each project proposal. Furthermore, the Ministry of Finance has prepared a draft decree to establish a unit in charge of programme and performance-based budgeting under the auspices of Deputy Minister of Finance.

Additionally, the Ministry of Planning, Monitoring and Administrative Reform is currently working on introducing an integrated electronic planning, monitoring, and evaluation system which links all public investment projects submitted by public entities to the goals and key performance indicators of the SDS. The software also requires all public investment allocation requests to outline the expected social, environmental, and economic impact of the project to enable decision-makers to prioritise the projects advancing the SDGs. The system ultimately aims at improving the efficiency and transparency of the planning, monitoring, and evaluation system and will be made obligatory starting in November 2019 for public investment projects in the 2019/2020 national plan and that will replace the existing paper-based method. ${ }^{24}$ The initiative has already been piloted by the Ministry of Foreign Affairs with regard to the EU funds in which programs are prioritised according to a number of factors including its relevance to the SDS.

While there is room for improvement, stakeholder engagement has been perceived as important: various consultations have been organised including by the Ministry of Planning, Monitoring and Administrative Reform and the National Council for Women. For example, the SDS is the first long-term strategy in Egypt that was developed following a participatory approach involving relevant stakeholders including the private sector, public and international organisations through the organisation of 150 specialised workshops and open meetings (The Government of Egypt, 2016). A number of experts, academics, and stakeholders from diverse backgrounds including women, people living with disability and young people participated in the consultations. The outcomes of consultation process were made available publicly (The Government of Egypt, 2016).

\section{Key challenges}

Egypt, like many countries, faces challenges in collecting and processing quality data and translating the data into policy useful knowledge. The prevalent challenges also relate to difficulties in ensuring vertical and horizontal coordination on the collection and use of data and in determining the kind of data that need to be collected across the levels of the government. For instance, the inadequacy of indicators at the governorate level has been recognised by Egypt as one of the major obstacles to the achievement of the Millennium Development Goals. It is crucial to strengthen the mechanisms on the collection and use of quality data at the sub-national level since the measurements at the national level may mask regional disparities.

\footnotetext{
${ }^{23}$ Ministry of Finance, Publication on the preparation of the 2018-2019 Budget

24 Official document provided by the Ministry of Planning, Monitoring and Administrative Reform (2018).
} 


\section{Quantitative performance indicators}

One of the key challenges also derives from the development of SDG indicators. Despite the progress achieved, having only 87 measurable and regularly updated indicators out of 232 global SDGs indicators poses challenges to tracking the progress over time and to evidence-based policymaking. Moreover, most of the Egypt-specific indicators are only available at the aggregate level (and in many cases have been transposed from the UN SDG indicator list), which threatens the availability and accessibility of data disaggregated by geographical location, sex, age, ethnicity and disability (The Government of Egypt, 2018b). The lack of disaggregated quality data also exacerbates the challenges related to the development of benchmarks and key performance indicators, notably Egypt-specific national- and regional-level outcomes-based ones. (The Government of Egypt, 2016).

Another challenge derives from the absence of a guiding framework for the collection and dissemination of statistics (World Bank, 2019). Enabling a unified and strategic approach can ensure that the statistical system is coordinated, well-resourced, and prepared to collect and disseminate the data needed to design, implement, and monitor sustainable development objectives.

\section{Skills}

Challenges deriving from lack of capacity, skills and resources also undermine the availability and use of quality data at the national and sub-national level. It is vital to ensure that line ministries and governorates have adequate capacity, skills and resources to collect, process and analyse quality data; identify the kind of data needed; and translate it into policy useful knowledge to follow up on the implementation of the SDGs. Given the existing capacity challenges, effectiveness, frequency and scale of the trainings need also to be enhanced. For instance, managing the transition to programme and performance-based budgeting requires providing trainings to over 650 budget units across the government.

\section{Moving to a performance/programme-based budget and linking the budget to the SDS}

Another key challenge derives from linking the national budget to the SDGs. As highlighted above, a lineitem budget prevents measuring the impact of budget allocations on the pursuit of the SDGs. Regarding the transition from line-item budgeting to programme and performance-based budgeting, there appears to be a lack of data and performance indicators as well as limited capacity and skills in line ministries. This poses challenges to manage the effective transition to programme and performance-based budgeting. Furthermore, the existing challenges in determining cost of service delivery, in conducting value for money analysis, and in performance auditing may undermine the efficient implementation of results-based budgeting.

\section{Strengthen stakeholder engagement capacity}

People's well-being constitutes the essence of Agenda 2030. Therefore, engagement of citizens in the design and implementation of the SDGs at all levels is of crucial importance to deliver effectively on the SDGs. In particular, this requires stakeholders from diverse backgrounds to be informed and consulted and actively engaged throughout the process to give the public greater voice on the pursuit of the SDGs.

Despite progress achieved in enhancing the stakeholder engagement, conducting consultations with diverse stakeholders is not mandatory and at the discretion of the entity. Therefore, given there is no guiding framework, consultations organised by different government bodies on SDGs can take different forms on an ad hoc basis. Thus, stakeholder consultation in the formulation, implementation and monitoring of national SDG plans requires to be institutionalised across the government through solid consultation and feedback mechanisms. This would also entail the establishment of systemic and participatory follow-up mechanisms to enhance citizen engagement. 


\section{References}

CAPMAS (2018) Population: Research \& Studies 69-13001-2018, 96th edition: July 2018,

CAPMAS (2018) SDG 2030 Performance Review Report, https://capmas.gov.eg/pdf/SDG.pdf

The Government of Egypt (2018a) Egypt's Voluntary National Review

https://sustainabledevelopment.un.org/content/documents/20269EGY VNR 2018 final with Hyperlink 9720185b45d.pdf

The Government of Egypt (2018b) SDG Observatory http://www.egyptsdgobservatory.info/\#/

The Government of Egypt (2016) Sustainable Development Strategy: Egypt Vision 2030

http://sdsegypt2030.com/wp-content/uploads/2016/08/English-Booklet-2030.compressed.pdf

OECD (2018), Policy Coherence for Sustainable Development 2018: Towards Sustainable and Resilient Societies, OECD Publishing, Paris. http://dx.doi.org/10.1787/9789264301061-en

OECD (2017), Getting Governments Organised to Deliver on the Sustainable Development Goals.

https://www.oecd.org/gov/SDGs-Summary-Report-WEB.pdf

OECD (2015) Policy Recommendations of the Council on Budgetary Governance, https://www.oecd.org/gov/budgeting/Recommendation-of-the-Council-on-Budgetary-Governance.pdf

The Ministry of Local Development (2017), http://mld.gov.eg/en/news/details/2035

The World Bank (2019), http://documents.worldbank.org/curated/en/310711565290546639/pdf/EgyptSupport-to-the-Preparation-of-First-National-Strategy-for-Development-of-Statistics-Project-AdditionalFinancing.pdf 


\section{Monitoring, Evaluation and Feedback Loops for SDG Implementation in Egypt}

\section{Significance of monitoring, evaluation and feedback loops}

Implementing a government vision and strategic plan on SDGs demands effective monitoring, evaluation and feedback frameworks to support more strategic, integrated and informed whole-of-government decision-making. Monitoring and evaluation systems, and feedback loops are crucial to ensure that public policy decisions and budget allocations contribute to the SDGs and to enable governments to alter course if results are not being achieved properly. In other words, sound monitoring, evaluation and feedback systems guarantee that policy choices are rooted in evidence-informed decisions, by providing a better understanding of what works and what does not. This also helps optimise policies' value for money, accountability and transparency, and therefore provide legitimacy for the use of public funds and resources. It is worthwhile underlining that policy monitoring is a descriptive tool referring to the systematic collection of data on specified indicators revealing the extent of progress and achievement of the objectives. Policy evaluation, on the other hand, is an analytical tool, which builds on the systematic and objective assessment of an ongoing or completed project or policy by demonstrating its design, implementation and results. Feedback loops refer to channels, which help ensure that the results of policy evaluation inform policy design and implementation.

Effective monitoring, evaluation and feedback systems require robust cross-government coordination led by the relevant centre of government institutions (CoG), involving data-collecting and producing bodies, line ministries and agencies as well as accountability and oversight bodies. This also entails enabling effective stakeholder engagement with citizens and civil society in the evaluation process to assess whether the efforts carried out by the government, including allocated financial resources, are producing the expected results and to make improvements based on the evidence provided through the engagement activity (see Box 3.1). Additionally, the availability, accessibility and the use of quality data and resultsbased performance indicators, aggregated nationally and broken down by region, is equally important to ensure a sound system for monitoring, evaluation and feedback. 


\section{Box 3.1. Monitoring and Evaluation of the SDGs}

\section{Tunisia}

Tunisia has established a National Technical Committee to monitor the implementation of its National Sustainable Development Strategy (2014-2020). The committee is composed of the Ministry of Foreign Affairs, the Ministry of Development, Investment and International Cooperation as well as sectoral focal points for SDGs, representatives of civil society, private sector and academia. In addition, SDG working groups within each ministry support the National Technical Committee.

These stakeholders were also consulted during the preparation of Tunisia's Voluntary National Review on the Implementation of the 2030 Agenda, presented to the UN High Level Political Forum in 2019.

\section{Morocco}

Morocco has set up a National Commission for Sustainable Development under the leadership of the Head of Government to ensure the coordination as well as monitoring and evaluation of the SDGs. The Commission takes place with the participation of the various ministerial departments, the High Commission for Planning and the national statistical agency. In this context, a statistical platform dedicated to the SDGs was developed to monitor and evaluate the SDGs on a regular basis. The National Commission for Sustainable Development is composed of two distinct committees:

- The committee in charge of monitoring the National Strategy for Sustainable Development is responsible for coordinating the actions of the various stakeholders for the implementation of decisions on the national strategy. It is also responsible for setting up a communication and awareness-raising programme around the objectives of this strategy, in addition to drawing up an annual activity report.

- The committee in charge of monitoring the implementation of SDGs defines priority SDGs to be achieved and monitor their implementation, in addition to coordinating the actions of stakeholders in this field.

\section{Czech Republic}

In the Czech Republic, the sustainable development agenda is coordinated at the national level by the Government Council on Sustainable Development (GCSD), chaired by the Prime Minister. The office of the Prime Minister has been chosen to the lead the GCSD to allow for cross-sectoral coordination and mainstreaming of sustainable development across policy areas.

One of the main tasks of the Council is to review the implementation of the strategic framework on sustainable development and the 2030 Agenda and reinforce the country's commitment to sustainable development.

The GCSD provides a platform for inter-sectoral policy coordination among central administrative authorities, ministries, and key stakeholders, such as the parliament, municipalities, NGOs, trade unions, academia and private sector. These stakeholders are represented in the GCSD as part of nine thematic committees and working groups; and actively participate in monitoring the implementation of the SDGs.

Source: Tunisia (2019), Voluntary National Review on the Implementation of the 2030 Agenda,

https://sustainabledevelopment.un.org/content/documents/23372Rapport_National_Volontaire_2019_Tunisie.pdf

https://sustainabledevelopment.un.org/memberstates/tunisia

Morocco (2020), Voluntary National Review on the Implementation of the 2030 Agenda,

https://sustainabledevelopment.un.org/memberstates/morocco

National Report on the Implementation of the 2030 Agenda for Sustainable Development, Czech Republic -National Voluntary Review (Office of the Government of the Czech Republic, 2017).

Government of the Czech Republic; and The Government Council for Sustainable Development of the Czech Republic.

https://www.vlada.cz/en/ppov/council-for-sustainable-development/the-government-council-for-sustainable-development-of-the-czechrepublic--153075/ 
OECD experience underlines the significance of integrating a set of government policy and planning tools systemically and as a whole across the government, both ex post and ex ante for effective monitoring and evaluation systems (OECD, 2012). This includes performance-based budgeting, regulatory impact analysis (RIA), sustainable impact assessments (SIA) and environmental impact assessments (EIA). For instance, Belgium introduced ex-ante impact assessment tool, the Sustainable Impact Assessment (SIA), which is integrated into the Regulatory Impact Assessment (RIA). The RIA assesses the impact of preliminary draft regulations on economic, social and environmental dimensions of sustainable development (OECD, 2018b).

This chapter examines key strengths and challenges of the current monitoring and evaluation systems, and feedback loops on the implementation of the SDGs in Egypt.

\section{Key strengths}

In line with the Egypt's commitment to the 2030 Agenda, the government has recognised monitoring, evaluation and feedback systems as an important pillar of the governing framework for the implementation of the SDGs. The significance Egypt has attached to the monitoring, evaluation and feedback systems has been embodied through the voluntary national reviews undertaken. Egypt volunteered for conducting two Voluntary National Reviews on the Sustainable Development Goals in 2016 and 2018 and for the ongoing MAPS Engagement ${ }^{25}$ on the SDG Implementation to collaborate with the international organisations including the UN, OECD and World Bank. This also demonstrates the commitment of the government to showcase the progress achieved in international and multilateral fora through monitoring and evaluation processes.

The efforts to strengthen the monitoring, evaluation and feedback frameworks have also involved the establishment of specialised monitoring and evaluation units in certain ministries and government bodies including in the Ministry of Planning, Monitoring and Administrative Reform and the Ministry of Investment and International Cooperation. Moreover, the Egypt SDG Observatory was launched to provide a digital platform for tracking progress towards the SDGs. The Observatory displays the data available for each SDG indicator in a comparative manner over time. ${ }^{26}$ Furthermore, some indicators provide data disaggregated by age and sex including those related to employment and education. The platform is publicly available.

In addition to the national observatory on the SDGs, a special observatory focusing on the SDGs and gender equality was established to monitor the implementation of the National Strategy for Women Empowerment (see Chapter 1). ${ }^{27}$ The strategy has translated the SDGs into 34 national indicators ${ }^{28}$ and specified a quantitative target for each indicator, which facilitates monitoring the progress. The Egypt National Observatory for Women is a publicly accessible digital platform, which provides data on the indicators of the national strategy and the SDGs. The platform also presents periodic reports on the status of the Egyptian women and the gender gap.

The ongoing transition from a line-item budget to programme/performance-based budgeting will also enable a more sound monitoring and evaluation process on pursuing the SDGs (see Chapter 2). In particular, it will help match public expenses and investments to goals and key performance indicators. Integrated electronic planning, monitoring, and evaluation system introduced by the Ministry of Planning,

\footnotetext{
${ }^{25}$ MAPS is the abbreviation for Mainstreaming, Acceleration and Policy Support.

26 The Egypt SDG Observatory, http://www.egyptsdgobservatory.info

27 The Egypt National Observatory for Women, http://www.enow.gov.eg/

28 The Government of Egypt (2017) National Strategy for the Empowerment of Egyptian Women 2030
} 
Monitoring and Administrative Reform also represents an important tool to align the budget allocations to the goals and key performance indicators of the SDS and SDGs (see Chapter 2). In short, integration of SDGs to the budget process will clearly benefit Egypt's monitoring, evaluation and feedback system on the SDGs.

Furthermore, the Ministry of Planning, Monitoring and Administrative Reform is currently planning to update the SDS in order to accommodate the major structural changes Egypt has witnessed. The process of updating the strategy could also act as an evaluation exercise, which takes stock of the progress, identifies the remaining gaps and informs the formulation of the new strategy.

\section{Key challenges}

\section{Data collection, processing and translation}

Challenges in realising effective monitoring and evaluation systems, and feedback loops on the SDGs are not unique to Egypt. One of the key common challenge several countries face relates to the effective use of feedback loops. As already acknowledged in the Voluntary National Review in 2018, Egypt faces particular difficulties in collecting robust, independently-verifiable data and translating it into policy-useful knowledge and using performance information to alter course where warranted (The Government of Egypt, 2018). The unavailability of some key performance indicators and data, in particularly data disaggregated by geographical location, sex, age, ethnicity or disability, also undermines the effectiveness of the SDG monitoring process. As mentioned in the chapter 2, the presence of only 87 measurable and regularly updated indicators out of 232 the global SDGs indicators poses important challenges to tracking the progress over time. This risks masking the existing gaps and bottlenecks; and constrains the formulation of appropriate policies. In addressing this issue, strengthening the evaluation and reporting ecosystem and establishing an integrated database on the SDGs will be of vital importance.

\section{Institutionalising coordination on the collection and use of data}

Challenges associated with institutionalised follow-up mechanisms with clear mandate and responsibilities also jeopardise a whole of government approach to strategic monitoring, evaluation and planning on the SDGs. Chapter 1 illustrates that the competences, working mechanisms and meeting frequency of the National Committee are not specified which undermines its monitoring and evaluation capacity. Furthermore, the Statistical Committee headed by CAPMAS appear to be ad hoc despite the existing legal basis. ${ }^{29}$ There is also a need to strengthen and revise the legal basis of CAPMAS in order to accommodate sources like big data, which currently lie beyond the competence of CAPMAS (The Government of Egypt, 2018). This could also include making an explicit reference to the SDGs in the mandate of CAPMAS. Disjointed efforts on the collection and use of data and the development of indicators may undermine sound monitoring and evaluation processes. This calls upon the centre of government institutions (CoG), data-collecting and producing bodies, line ministries and agencies as well as accountability and oversight bodies to coordinate better on the SDG monitoring and evaluation.

\section{Assessing performance for impact}

The application of governance tools such as regulatory impact analysis (RIA), sustainable impact assessments (SIA), and environmental impact assessments (EIA) is not mandatory and appears to be patchy across different policy areas. Evidence across the OECD demonstrates that systemic application of regulatory impact analysis (RIA), sustainable impact assessments (SIA), and environmental impact

${ }^{29}$ The Government of Egypt, Presidential Decree 2915/1964. 
assessments (EIA), both ex post and ex ante, helps deliver more effectively on the SDGs by requiring economic, social and environmental aspects to be taken into account in all strategic planning documents.

Furthermore, results-based management tools could be used to inform all dimensions of management and decision making to achieve the SDGs. The OECD Guiding Principles on Managing for Sustainable Development Results underlines that results information should systematically be used for learning and decision-making in order to improve delivery and enhance impact (OECD, 2019). This suggests that quantitative and qualitative data and evidence from monitoring and evaluation should be used for strategic management, operational and change management processes, and performance and knowledge management across levels of government.

\section{References}

The Government of Egypt (2018) Egypt's Voluntary National Review

https://sustainabledevelopment.un.org/content/documents/20269EGY VNR 2018 final with Hyperlink 9720185b45d.pdf

The Government of Egypt (2017) National Strategy for the Empowerment of Egyptian Women, 2030, http://ncw.gov.eg/wp-content/uploads/2018/02/final-version-national-strategy-for-the-empowerment-ofegyptian-women-2030.pdf

OECD (2019), The Guiding Principles on Managing for Sustainable Development Results, http://www.oecd.org/dac/results-development/docs/mfsdr-guiding-principles.pdf

OECD (2018a), Policy Coherence for Sustainable Development 2018: Towards Sustainable and Resilient Societies, OECD Publishing, Paris. http://dx.doi.org/10.1787/9789264301061-en

OECD (2018b) Strategic Environmental Assessment and Environmental Impact Assessmenthttp://www.oecd.org/fr/env/ouverture/eapgreen-sea-and-eia.htm

OECD (2015) Policy Recommendations of the Council on Budgetary Governance, https://www.oecd.org/gov/budgeting/Recommendation-of-the-Council-on-Budgetary-Governance.pdf

OECD (2012) Policy Recommendations of the Council on Regulatory Policy and Governance, https://www.oecd.org/governance/regulatory-policy/49990817.pdf

The Egypt National Observatory for Women, http://www.enow.gov.eg/

The Egypt SDG Observatory, http://www.egyptsdgobservatory.info 


\section{The Way Forward}

This Report takes stock of significant process Egypt has made on the implementation of the SDGs. Among them, a strong commitment and ownership at the highest political level, the preparation of the first sustainable development strategy of Egypt and the recognition of institutional coordination mechanisms reveal considerable dedication and efforts undertaken by the government of Egypt.

Despite progress, significant challenges in governance related to inter-institutional coordination, policy coherence, collecting and processing evidence/data into policy-useful knowledge, and limited capacity, skills and awareness across levels of government undermine the formulation and implementation of appropriate policy responses to economic and structural challenges. While it is beyond the scope of this paper, it is worthwhile to underline that important challenges related to lack of transparency and accountability frameworks as well as public integrity systems also persist. Effective, inclusive, transparent and accountable public institutions are key to address these challenges and ensure that ongoing reform efforts in different policy areas are sustainable and complementary to each other. Evidence across the OECD and MENA countries demonstrates that a number of governance frameworks and tools could help foster Egypt's ongoing efforts in pursuing the SDGs and could help Egypt unlock its untapped potential.

In light of the findings of this report and based on the good practices across the OECD countries, the following recommendations are applicable to implement the SDGs in most effective and efficient manner. Each of the policy recommendations is illustrated with good practice examples from the OECD countries that could be considered by Egypt in charting a course for achieving better outcomes in pursuing the SDGs.

\section{Specific Recommendations}

\section{Strengthen institutional and decision-making arrangements for SDG implementation}

- Sustain high-level political commitment and support for the effective implementation of the SDGs. This could also help reinforce the commitment and ownership of all parties engaged in the SDGs.

Support could be generated at three levels:

- At the highest political level to sustain strong commitment to the implementation of the SDGs;

- Across the public administration to implement the SDS and SDGs; avoid resistance to the change; and ensure that they feel the ownership of the SDGs at the national and sub-national level; and

- Across the society to generate trust in the ongoing reform agenda.

Experience of the OECD countries demonstrates that support for the implementation of the 2030 Agenda could be enhanced through different means. Based on OECD experience, a formal announcement by the government which calls for effective implementation of the SDGs is critical to ensure high-level political commitment. Anchoring and aligning this commitment across the government through mandate letters signals priorities to ministers and their departments, and reinforces effective implementation of the SDGs. 
For instance, in France, each "directeur d'adminstration centrale" receives a mandate letter with objectives to be met (OECD, 2017).

In Egypt, the 2030 Agenda for Sustainable Development could be directly reflected within the mandates of all ministers who are expected to deliver on the SDGs. Based on this mandate, consideration could be given to integrating SDGs into the annual performance evaluation of senior public officials, particularly the top ranks including ministers, as a measurement of their performance against the achievement of the SDS and SDGs (in addition to assessing their performance against the core competencies of the position they occupy). Given the multidimensional nature of the SDGs, this can also encourage senior civil servants to collaborate more effectively across institutional silos to achieve multi-sector policy outcomes on the SDGs more effectively.

Another critical measure to foster support and commitment across the public administration for the implementation of the 2030 Agenda could be through strengthening the enabling legal and regulatory framework on the SDGs. This includes allocating clear roles and responsibilities to the members of the National Committee for Monitoring the Implementation of the SDGs and making them accountable about their responsibilities. In addition, information related to the implementation of the SDGs and SDS including decisions taken at the National Committee as well as performance evaluations could be made public in order to sustain support, commitment and ownership across the society and generate trust in the ongoing reform agenda. For example, Canada made all ministerial mandate letters public in November 2015 in order to give citizens a clear idea of how the Government will deliver its agenda. Mandate letters outline the policy objectives each minister will work to accomplish and allows Canadians to see the Prime Minister's expectations for each minister. ${ }^{30}$

- Optimise the use of the centre-of-government institutions (CoG) in enabling a whole-of-government approach to the SDG implementation and reinforce the role of the CoG through the involvement of Prime Minister and Presidential offices in leading the pursuit of the SDGs. The existing institutional framework governing the implementation of the SDGs underlines the importance for the Ministry of Planning, Monitoring and Administrative Reform and Ministry of Finance to steer the pursuit of the SDGs. The ongoing efforts to establish "High Council for Planning and Sustainable Development" under the leadership of the President and with the membership of the Prime Minister demonstrates the necessity to involve the offices of Prime Minister and President among the CoG institutions leading the SDG implementation. This also implies the need to create strong cooperation between the Ministry of Planning Monitoring and Administrative Reform, Ministry of Finance and Prime Minister and Presidential offices on the pursuit of the SDGs.

Across the OECD, the involvement of the Prime Minister and Presidential offices has proven effective since these institutions have expertise in working on crosscutting policy areas and convening power to mobilise all government bodies across all levels. In two-thirds of the OECD countries, the offices of Prime Ministers and Presidents lead the SDG implementation efforts (see Box 4.1) (OECD, 2016). Egypt might consider allocating greater role to the Prime Minister and Presidential offices in leading the implementation of the SDGs. For instance, "High Council for Planning and Sustainable Development" which is planned to be established under the auspices of the President could be used to serve this purpose.

\footnotetext{
${ }^{30}$ The Government of Canada (2018) https://pm.gc.ca/eng/news/2018/08/28/prime-minister-releases-new-ministerialmandate-letters
} 


\section{Box 4.1. The centre-of-government coordination of the SDGs}

\section{Finland}

In 2016, the Prime Minister's Office of Finland started assuming responsibility for coordinating the national implementation of Agenda 2030 and the national sustainable development policy, within the framework of the Finnish National Commission on Sustainable Development. A Coordination Secretariat in charge of planning, preparing, coordinating and ensuring the national implementation of Agenda 2030 was established in the Prime Minister's Office. The Secretariat comprises representatives of the Secretariat General of the Finnish National Commission on Sustainable Development, the Ministry for Foreign Affairs and the Prime Minister's Office.

Furthermore, the Sustainable Development Coordination Network, consisting of representatives of key Ministries, supports and guides the work of the Coordination Secretariat. The Network is responsible for the coordination of sustainable development between administrative sectors for almost twenty years. It prepares, develops and coordinates sustainable development efforts in Finland, with the objective of increasing policy coherence and mainstreaming sustainable development, while also preparing the work of the Finnish National Commission on Sustainable Development. Members of the Coordination Network act as focal points of sustainable development within their respective areas of government. Each member of the Network integrates the views of his or her administrative branch with the national sustainable development plan and sustainable development work. The Network convenes ten times a year.

As the coordinator of the national implementation of Agenda 2030, the Prime Minister's Office brings credibility to the implementation work, while the Sustainable Development Coordination Network, covering all branches of government, provides a strong basis for policy coherence. The SDG agenda was originally housed in the Ministry of Finance but was moved to strengthen policy coherence.

Source: National report on the implementation of the 2030 Agenda for Sustainable Development Finland, 2016

- Ensure multi-dimensionality in the design and implementation of the SDS while aligning all sector-based strategies with the SDS, national priorities and the SDGs themselves. The strategy should introduce short and medium term action-oriented goals to facilitate the monitoring of the progress.

For instance, establishing a formal framework of cooperation across government institutions for the development of sector-based strategies could optimise the alignment of all sector-based strategies with the SDS and SDGs. In addition, this could help all ministries work together, analyse the potential linkages in order to maximise the multidimensionality within sector-based strategies as well as the coherence between them, and identify and manage trade-offs and spill-overs successfully. The existing National Committee and the planned High Council could provide a platform for such collaboration and debate.

In addition, OECD experience shows that sector-based plans and strategies need to include the SDGs at goal, target and indicator level in their prioritisation and results frameworks to ensure alignment towards the SDGs across policy areas (OECD, 2019). In particular, results planning across sectors is advised to be synchronised with relevant SDG indicators.

- As part of optimising the use of the CoG in whole-of-government strategysetting and steering, pursue the transition of the National Budget toward an integrated results-based budget, align the results-based budget areas with the sustainable development objectives for the country in the SDS, and ensure that these SDS objectives fully reflect the SDGs. In the context of optimising the CoG, this implies strengthening and sustaining institutional coordination between MoPMAR and the Ministry of Finance (and the Presidency).

- Strengthen vertical and horizontal coordination by ensuring compliance with the existing rules, formalising the coordination mechanisms in place and ensuring their effective use. Ensuring that the existing National Committee and the planned High Council acts as an inclusive platform and as a bonding 
mechanism across levels of government is crucial to its success. In this regard, the ongoing efforts toward establishing a sub-committee at the governorate level would help enhance vertical coordination. Additionally, the participation of governorates in the existing National Committee and the planned High Council could help ensure that specifics of different places in Egypt are reflected in the national strategy and action plans (see Box 4.2). A strong cooperation between the Ministry of Local Development and the Ministry of Planning Monitoring and Administrative Reform is also essential to steer the pursuit of the SDGs at the subnational level. Within this framework, further attention could be paid to allocate clear responsibilities on the implementation of the SDGs within their mandates to prevent mandate overlap/duplication and to enable jointed efforts in this regard.

Experience of the OECD countries demonstrates that the competences, meeting frequency and working mechanisms of the inter-institutional body need to be clearly defined for its effective use. For instance, in the cases of Netherlands, Germany and Austria, inter-institutional bodies on the implementation of SDGs meet on a regular basis to address important crosscutting or sectoral issues on a consensus basis (OECD, 2018a). Therefore, it is essential for Egypt to further institutionalise and formalise the structure and mandate of the existing National Committee and the planned High Council. In doing so, Egypt might consider:

- Allocating clear responsibilities to the members of the inter-institutional body, including to the Rapporteur and Chair;

- Specifying working mechanisms of the inter-institutional body;

- Creating legal basis for sub-committees, which operate as part of the interinstitutional body, with clear mandates, structures and responsibilities;

- Introducing short and medium term action plans, goals and agendas which will guide the committee's actions (e.g. annual and pluriannual);

- Following up regularly on the implementation of the actions outlined by the interinstitutional body;

- Specifying meeting frequency and timetable for all committee meetings; and

- Sharing minutes of meetings as well as results and decisions taken with all members on a regular basis.

Furthermore, it is also critical to institutionalise SDG and equal opportunity units across all ministries with coherent, clear and effective mandates, structures and responsibilities. While it is important to institutionalise the coordination mechanisms, priority should be given to operationalising and simplifying the existing processes and procedures, and making them effective rather than creating new structures. In this context, administrative simplification methods used across OECD countries, including reviews of the stock of regulations; reduction of administrative burdens; simplification of administrative procedures; multilevel co-ordination and e-government services, could help Egypt pursue an administrative simplification agenda.

Evidence across the OECD countries demonstrates that a number of incentives and tools could be adopted by Egypt to foster vertical and horizontal co-ordination. For instance, $86 \%$ of OECD countries reported using financial incentives or assessing inter-institutional coordination as a function of individual or collective performance targets to promote horizontal cooperation (OECD, 2013). In the context of Egypt, consideration could be given to the use of following incentives and tools to ensure coordination and compliance:

- Individual or collective performance evaluation targets could be used to incentivise ministries to work together. The performance targets on the implementation of SDGs could be output-based (such as number of meetings) or performance-based (such as better educational outcomes, better jobs and less poverty) which could be integrated into evaluation frameworks used to measure the performance of senior public officials or institutional bodies. Furthermore, knowing that part of their 
annual performance assessment evaluates cross-ministry co-ordination serves as a powerful incentive for senior public officials to collaborate.

- Financial incentives could be offered to drive policy co-ordination on the SDGs. This implies providing greater financial flexibility for resources to be shared between ministries and allocating these resources to where they can best contribute to achieving SDGs. Given the crosscutting nature of SDGs, financial incentives could be useful to enable a lead ministry with a particular multi-sector task to encourage other ministries to deliver on their part of the task. In the case of Egypt, MoPMAR, for example, could have funding targeted at crosscutting projects on the SDGs, which could be used to incentivise other ministries to work together on transversal tasks.

\section{Box 4.2. Strengthening vertical coordination}

\section{Mexico}

Mexico established the National Council for the 2030 Agenda for Sustainable Development, which brings together all state secretaries and is chaired by the President. The Council co-ordinates actions for the design, implementation and evaluation of policies to comply with the 2030 Agenda and aims at aligning efforts at the federal, state and municipal levels. With this purpose, the National Governors' Conference (CONAGO) established an Executive Committee for Compliance with the 2030 Agenda. Twenty-one Mexican states currently have state commissions to support SDG implementation at the sub-national level.

\section{Finland}

In Finland, all cities and regions have representatives in the National Commission on Sustainable Development, which is led by the Prime Minister.

Source: Mexico (2017), Guia para incorporar el enfoque de la Agenda 2030 en la elaboración de planes estatales y municipales de desarrollo, Oficina de la Presidencia de la República, Ciudad de México,

https://www.gob.mx/cms/uploads/attachment/file/255731/Gu a enfoque A2030 para entidades y municipios comp.pdf PMO Finland (2017), Government Report on the implementation of the 2030 Agenda for Sustainable

Development. Sustainable Development in Finland - Long-term, Coherent and Inclusive Action, https://julkaisut.valtioneuvosto.fi/bitstream/handle/10024/79455/VNK_J1117_Government_Report_2030Agenda_KANSILLA_netti.pdf? sequence $=1$

- Strengthen vertical coordination by enhancing the capacity of the governorates and by reflecting bottom up priorities in the national strategy. This requires equipping each governorate with the capacity to coordinate with the national government on strategy setting, collecting, processing and sharing sound regional performance data and evidence; and to engage effectively with their region's citizens and stakeholder groups.

- Design and implement a sustained communication strategy to raise awareness and to ensure sustained support for the successful implementation of the SDGs. This entails:

- Raising awareness across the system and in the governorates on the nature, scope and purpose of institutional arrangements;

- Creating and encouraging ownership of the SDG agenda at the sub-national level. 


\section{Make effective use of governance tools for SDG implementation}

- Ensure that the sustainable development strategy (SDS) is embedded into a broader "whole-of-government" approach for SDG governance and supported by application of various governance policy tools such as public consultation mechanisms, impact assessments and results-based budgeting. This also involves an effective and systemic application of regulatory impact assessments (RIA), sustainable impact assessments (SIA), and environmental impact assessments (EIA) (see Box 4.3).

\section{Box 4.3. Assessing performance for impact}

\section{Germany}

It is mandatory in Germany to assess the impact of all proposed laws and regulations on the principle of "sustainable development". Within the framework of the Sustainability Impact Assessment (SIA), Germany has also introduced an online tool to assess the proposed laws and regulations vis-à-vis the German Sustainable Development Strategy as well as SDGs. The SIA serves as an instrument to check whether and how intended legislation contributes to implementing Germany's National Sustainability Strategy. All draft bills are evaluated by the Parliamentary Advisory Council on Sustainable Development to conduct quality assurance for the SIA.

\section{Belgium}

Belgium introduced ex-ante impact assessment tool, the Sustainable Development Impact Assessment (SDIA), which is integrated into the Regulatory Impact Assessment (RIA). SDIA, made a mandatory requirement in 2007 , screens the impact of draft regulations in terms of sustainable development. Therefore, the RIA assesses the impact of preliminary draft regulations on economic, social and environmental dimensions of sustainable development.

The RIA (including SDIA) is one of the documents that must be presented to the Council of Ministers along with the draft regulation for approval. Officials in charge of drafting regulations, such as members of ministerial cabinets and/or members of administrations, are responsible for filling in the impact assessment form.

Source: Germany (2016), German Sustainable Development Strategy. New Version 2016, The Federal Government, https://www.bundesregierung.de/Content/DE/_Anlagen/Nachhaltigkeitwiederhergestellt/

2017-06-20-nachhaltigkeit-neuauflage-engl.pdf? _blob=publicationFile\&v=2; www.enap.bund.de; https://www.polsoz.fuberlin.de/polwiss/forschung/systeme/ffu/files/SIA-Study_2011_Jacob_ex.pdf

OECD (2018), Policy Coherence for Sustainable Development 2018: Towards Sustainable and Resilient

Societies, OECD Publishing, Paris. http://dx.doi.org/10.1787/9789264301061-en OECD (2015) https://www.oecd.org/gov/regulatorypolicy/Impact-assessment-in-Belgium-June-2015\%20fr.pdf

- Institutionalise the application of public consultation mechanisms in the formulation; implementation and monitoring of national SDG plans across the government through solid consultation and feedback mechanisms (see Box 4.4). In particular, further efforts could focus on establishing a uniform framework clearly outlining how diverse stakeholders from the public, civil, academic and private sectors can be involved in all phases of the policy-cycle and in the service design and delivery. This could also help foster transparency, ownership and commitment across the society by enabling a citizen-centred and participatory approach to the implementation of the SDGs. 


\section{Box 4.4. Institutionalising stakeholder consultation}

\section{Slovak Republic}

The Slovak Republic has established the Chamber of Stakeholders under the Working Group for the Implementation of the 2030 Agenda for Sustainable Development, which is the main coordinating body for the implementation of the 2030 Agenda. The Chamber of Stakeholders is composed of representatives of forty key stakeholders including civil society organisations, think tanks, universities, academia, municipalities, regions, business associations and trade unions.

The Chamber has been formed to formulate the national priorities for the 2030 Agenda and actively monitor the activities taking place in each thematic area of the SDGs. For instance, the Chamber of Stakeholders expanded the five national priorities initially proposed by the government by adding a sixth national priority focusing on the rule of law, democracy and security, with an objective to highlight the human rights aspects of sustainable development.

Source: Slovak Republic (2013) Voluntary National Review of the Slovak Republic on the Implementation of the 2030 Agenda for Sustainable Development - Deputy Prime Minister's Office for Investments and Informatization of the Slovak Republic.

https://sustainabledevelopment.un.org/content/documents/20131Agenda2030 VNR Slovakia.pdf

- Enhance policy coherence for implementation of the SDGs. According to the 65 Voluntary National Reviews presented by UN members to the UN High-level Political Forum, coordinating across policy areas and enhancing policy coherence is identified as one of the most challenging aspects of pursuing the SDGs. In the case of Egypt, the challenges to policy coherence derive from aligning all sectorbased strategies with the SDGs and enabling a whole-of-government approach The efforts to address existing challenges and strengthen policy coherence could build on following elements:

- Fostering synergies across economic, social and environmental policy areas;

- Identifying trade-offs and reconcile domestic policy objectives with internationally agreed objectives;

- Addressing the negative spill overs of domestic policies (OECD, 2018a);

- Integrating sustainable development goals into the mandate of existing institutions while allocating clear responsibilities; and

- Assessing mandate overlaps, avoiding duplication of efforts and conflicting competences.

The existing National Committee and the planned High Council could provide a platform to explore synergies, assess spill-overs and manage trade-offs across institutional silos. The integration of SDGs into mandates of institutions as well as mandate overlaps could be addressed through the new state planning law. 
- Strengthen the collection, analysis, dissemination and use of quality data. As acknowledged in the Voluntary National Review in 2018, Egypt faces particular challenges in operationalising evidence in the decision-making process, as is the case with many OECD countries. Egypt could further invest in capacity to produce quality and disaggregated data and transform the information generated into policyrelevant knowledge. Additionally, there is room to enhance the use of performance information in budget setting and execution. In doing so, consideration could be given to:

- Ensure an effective transition to results-based budgeting and link the SDGs to programme areas in results-based budgeting (see recommendation above on linking the budget to the SDS and the SDGs and Box 2.1);

- Align outcome-based KPls to programme and performance-based budgeting;

- Make full use of the newly created electronic planning, monitoring, and evaluation system to align the budget allocations to the goals and key performance indicators of the SDS and SDGs;

- Provide a clear mandate and adequate human and financial resources to the Central Audit Agency to conduct performance and value for money audits;

- Sustain engagement with all stakeholders while collecting data that can serve to inform SDG indicators across the national and sub-national level. This also calls upon consolidating a robust coordination across the centre of government institutions (CoG), data-collecting and producing bodies, line ministries and agencies as well as accountability and oversight bodies (see Box 4.5). 


\section{Box 4.5. Strengthening evidence-based policymaking}

\section{Portugal}

The National Institute for Statistics of Portugal (Statistics Portugal) plays a key role in enabling coordination with the statistical departments of different ministries and other national authorities involved in SDG implementation at the national level. This helps Statistics Portugal identify appropriate data sources and map out available indicators for monitoring the SDGs in Portugal. A single SDG platform allowing an overview of SDG indicators has been launched on Statistic Portugal's website and made publicly available. The leadership of the central statistics agency of Portugal has also helped facilitate consistency across different levels of monitoring and reporting efforts.

\section{Norway}

Following the adoption of the 2030 Agenda, Norway has incorporated the national reporting mechanism on the SDGs into the budget process. The Ministry of Finance is responsible for ensuring a co-ordinated budget to foster SDG implementation and allocates each of the 17 SDGs to a specific co-ordinating ministry. These ministries collaborate with other ministries involved in following up the relevant targets. Ministries prepare annual progress reports, which are compiled by the Ministry of Finance and submitted to the Norwegian parliament as part of the national budget.

Source: OECD (2018), Policy Coherence for Sustainable Development 2018: Towards Sustainable and Resilient Societies, OECD Publishing, Paris. http://dx.doi.org/10.1787/9789264301061-en

UNDESA (2017) Overview of institutional arrangements for implementing the 2030 Agenda at national level. https://sustainabledevelopment.un.org/content/documents/10735Updated_Issues_Brief_rev10_1_March_2017.pdf

- Provide trainings and tools to strengthen the skills and capacities across levels of governments to ensure the availability and accessibility of quality and disaggregated data as well as the analytical capacity to translating the data into policy useful knowledge.

- Set measurable performance indicators aligned with the SDS and SDGs. Ensure the strategic use of performance indicators and data across the public sector in order to support the monitoring and evaluation of the impact of sustainable development strategy and initiatives (see Box 4.6).

\section{Box 4.6. Strategic use of performance indicators}

\section{Finland}

Finland has developed a plan to introduce sustainable development objectives in the performance targets and performance management of the ministries and government agencies. This also involves the inclusion of sustainable development objectives in the performance targets and follow-up indicators in the budgetary planning process.

Source: PMO Finland (2017), Government Report on the implementation of the 2030 Agenda for Sustainable Development. Sustainable Development in Finland - Long-term, Coherent and Inclusive Action, https://julkaisut.valtioneuvosto.fi/bitstream/handle/10024/79455/VNK J1117 Government Report 2030Agend a KANSILLA netti.pdf?sequence $=1$ 
Enable sound monitoring, evaluation and feedback loops for SDG implementation

- Commit to report regularly on the implementation of the measures outlined in the sustainable development strategy. Regular monitoring and evaluation of the implementation allows for measuring the effectiveness of implementation through tracking progress over time; accountability, reveals potential bottlenecks and encourages the formulation of appropriate responses. Effective monitoring and evaluation could be ensured through following measures:

- Formalise the strategic monitoring and evaluation systems and feedback loops by institutionalising and making full use of the existing National Committee and the planned High Council;

- Ensure that the performance evaluation is publicly available (see Box 4.7).

\section{Box 4.7. Sound monitoring and evaluation systems}

\section{Belgium}

Belgium has integrated the commitment to report periodically on the implementation of the SDGs into its National Sustainable Development Strategy. All the relevant authorities collectively report on the implementation of the 2030 Agenda twice per government term and engage in a dialogue with the key stakeholders including civil society, private sector and parliaments.

\section{Czech Republic}

In Czech Republic, progress towards national goals are measured by the biannual analytical "Report on Quality of Life and its Sustainability", which builds on indicators operationalising the 97 specific goals outlined in the Czech Republic 2030 strategy. The Government Council on Sustainable Development, the main coordinating body for the implementation of the $2030 \mathrm{Agenda}$, is responsible for reviewing the implementation at the national level. The Czech Statistical Office plays a key role in providing relevant data and leading the co-ordination related to the global set of indicators.

Source: PMO Belgium (2017), Pathways to Sustainable Development. First Belgian National Voluntary

Review on the Implementation of the 2030 Agenda,

https://sustainabledevelopment.un.org/content/documents/15721Belgium_Rev.pdf.

Office of the Government of the Czech Republic (2017), National Report on the Implementation

of the 2030 Agenda for Sustainable Development Czech Republic,

https://sustainabledevelopment.un.org/content/documents/15717Czech_Republic.pdf.

- Monitor and evaluate the implementation and effectiveness of the institutional and decision making arrangements on a regular basis to make sure that they serve best to implement the SDS and SDGs. This entails:

- Evaluate the system every three years to measure and analyse the impact and results; and adjust course where necessary to improve coherence and performance against outcomes;

- Establish functioning central steering and strategy review processes;

- Update and revise the national sustainable development strategy regularly to take account of the progress and structural changes made. 


\section{Strengthen the institutional framework governing the implementation of gender equality and SDG 5}

- Pursue gender mainstreaming in the design, development, implementation and evaluation of all policy areas and budgets with a view to make progress in SDG 5, and support the implementation of SDS through a more gendersensitive lens. Consideration could also be given to institutionalising and formalising the coordination mechanisms between line ministries and the Centre of Government with the National Council for Women to pursue gender mainstreaming across all policy areas. Furthermore, Egypt might consider adopting gender impact assessment tools in support of evidence-based decision-making (see Box 4.8.).

\section{Box 4.8. Integrating national gender equality strategies into SDG agendas}

As part of its Policy for Global Development, Sweden has made gender equality a core priority of its national strategy, identifying gender equality budgeting as a strategic tool to meet Goal 5 and thus ensure the implementation of the 2030 Agenda. In Mexico, gender mainstreaming has been incorporated as a transversal requirement in realisation of the National Development Plan. The Netherlands is currently working on implementing SDG5 through the introduction of a quality requirement 'Effects on Gender equality'. Paraguay targeted gender mainstreaming in SDG implementation through establishing gender equality as a cross-cutting priority in its National Development Plan (PND 2030).

Source: OECD (2019), Governance as an SDG Accelerator: Country Experiences and Tools, OECD Publishing, Paris, https://doi.org/10.1787/0666b085-en.

- Bolster the capacity and resources of the National Council for Women and of line ministries to develop, implement and monitor National Strategy for the Empowerment of Egyptian Women 2030, and to enable a whole-ofgovernment approach across policy fields and SDGs. The OECD Recommendation on Gender Equality in Public Life (2015) stresses that gender equality institutions need to have sufficient capacity and resources to be able to coordinate a government-wide initiative and enjoy the visibility and authority that are often obtained by being placed at the highest level of government.

- Strengthen accountability and oversight mechanisms for the effective implementation of the National Strategy for the Empowerment of Egyptian Women 2030 and gender mainstreaming. The 2015 OECD Recommendation underlines that independent institutions shall have adequate mandate and capacity to monitor implementation of government-wide gender equality and mainstreaming policy. Further consideration could be given to mandating the Central Audit Agency of Egypt to provide oversight for implementing National Strategy for the Empowerment of Egyptian Women 2030.

- Adopt measures to achieve gender-balanced representation in parliaments, judiciary and public administration and improve gender equality in public sector leadership. In public sector, further consideration could be given to the use of proactive gender-sensitive people management policies such as work-life balance and family-friendly policies including flexible working hours, part-time work and maternity, paternal and parental leave arrangements. Additionally, disclosure requirements, target setting or quotas, open competition, clear recruitment standards and wide vacancy advertisements could be used further to promote equal access to opportunities in public sector leadership. As for the representation of women in the parliament, Egypt might consider reviewing the Law 46/2014 which sets a minimum number of seats for women in the House of Representatives,

31 The law sets a minimum number of seats for women in the House of Representatives. 
with a view to increasing the number of women represented in the parliament. Consideration could be also given to introducing measures to ensure compliance with the law such as through the rejection of non-complaint party lists by the electoral management body or financial penalties.

- Eliminate any gender pay gap in public and private sector as well as occupational segregation. The efforts could build on the labour law that guarantees equal pay for equal work through introducing systemic and regular pay assessments. According to a study conducted by the Central Statistics Agency (CAPMAS), a high percentage of Egyptian women are concentrated in jobs that are placed at the bottom of the career ladder, which, in turn, leads to less earned income compared to men who work in the same jobs. The same study estimates the gender pay gap as almost EGP 168 per month (CAPMAS, 2018). In addressing this issue, consideration could be given to performing regular audits and establishing independent complaint and legal recourse mechanisms for noncompliance.

In applying these recommendations, Egypt might consider establishing a set of priorities and codifying them into a strategic and actionable implementation plan identifying a timeline with short and medium-term action-oriented goals. The implementation plan could benefit from listing a sequence of actions based on the priorities and available human and financial resources. In particular, sequencing of priorities should take account of the implementation of tools and processes that require longer time spans as well as more advanced capacities such as the evolution away from line-item budgeting to programme and performancebased budgeting. It is also advisable to better assess interlinkages across the SDGs and to identify potential 'accelerators' that could be prioritised in the short-term (see MAPS Work Package 1 for key policy recommendations on the SDG interlinkages and potential accelerators) ${ }^{32}$. However, many actions suggested by the above-mentioned recommendations are complementary to each other and would have to be pursued simultaneously.

\section{References}

CAPMAS (2018), Population: Research \& Studies 69-13001-2018, 96th edition: July 2018. https://www.capmas.gov.eg/Pages/StaticPages.aspx?page id=5084

OECD (2019), Sustainable Results in Development: Using the SDGs for Shared Results and Impact, OECD Publishing, Paris, https://doi.org/10.1787/368cf8b4-en.

OECD (2018), Policy Coherence for Sustainable Development 2018: Towards Sustainable and Resilient Societies, OECD Publishing, Paris. http://dx.doi.org/10.1787/9789264301061-en

OECD (2017), "The Organisation and Functions of the Centre of Government".

OECD (2016), Survey on Planning and Co-ordinating the Implementation of the Sustainable OECD (2013), Survey on the Organisation and Functions of the Centre of Government, OECD, Paris.

The Government of Canada (2018) "Prime Minister releases new ministerial mandate letters" https://pm.gc.ca/eng/news/2018/08/28/prime-minister-releases-new-ministerial-mandate-letters (accessed 2 September 2019)

\footnotetext{
32 UNDP (2018), MAPS Engagement for Egypt 2018-2019, Mainstreaming Acceleration and Policy Support (MAPS) for SDGs, SDG interlinkages and potential accelerators, https://www.undp.org/content/dam/egypt/docs/Publications/Docs\%20SDGs/Policy\%20Note\%20SDGs\%20\%20MAPS\%20Engagement\%20for\%20Egypt\%202018-2019.pdf
} 